\title{
BEDT-TTF Salts Formed with Tetrahedrally Coordinated Zinc(II) Complex Anions
}

\section{$\operatorname{AUTHOR}(S)$ :}

Yoshida, Yukihiro; Ito, Hiroshi; Nakamura, Yuto; Ishikawa, Manabu; Otsuka, Akihiro; Hayama, Hiromi; Maesato, Mitsuhiko; Yamochi, Hideki; Kishida, Hideo; Saito, Gunzi

\section{CITATION:}

Yoshida, Yukihiro ...[et al]. BEDT-TTF Salts Formed with Tetrahedrally Coordinated Zinc(II) Complex Anions. Crystal Growth \& Design 2016, 16(11): 6613-6630

\section{ISSUE DATE:}

2016-09-27

URL:

http://hdl.handle.net/2433/219020

\section{RIGHT:}

This document is the Accepted Manuscript version of a Published Work that appeared in final form in 'Crystal Growth \& Design', copyright (C) American Chemical Society after peer review and technical editing by the publisher. To access the final edited and published work see http://doi.org/10.1021/acs.cgd.6b01294.; The full-text file will be made open to the public on 27 September 2017 in accordance with publisher's 'Terms and Conditions for Self-Archiving'.; この論文は出版 社版でありません。引用の際には出版社版をご確認ご利用ください。; This is not the published version. Please cite only the published version. 


\section{Cover Page}

Title: BEDT-TTF Salts Formed with Tetrahedrally Coordinated Zinc(II) Complex Anions

Authors: Yukihiro Yoshida,* Hiroshi Ito, Yuto Nakamura, Manabu Ishikawa, Akihiro Otsuka, Hiromi Hayama, Mitsuhiko Maesato, Hideki Yamochi, Hideo Kishida, and Gunzi Saito

Affiliations: Faculty of Agriculture, Meijo University, Tempaku-ku, Nagoya 468-8502, Japan, Department of Applied Physics, Nagoya University, Chikusa-ku, Nagoya 464-8603, Japan, Division of Chemistry, Graduate School of Science, Kyoto University, Sakyo-ku, Kyoto 606-8502, Japan, Research Center for Low Temperature and Materials Sciences, Kyoto University, Sakyo-ku, Kyoto 606-8501, Japan, Toyota Physical and Chemical Research Institute, Nagakute 480-1192, Japan

Abstract: 12 kinds of bis(ethylenedithio)tetrathiafulvalene (BEDT-TTF or ET) cation salts with tetrahedrally coordinated zinc(II) complex anions were obtained by electrocrystallization; most of them were produced via the additional reaction of Lewis-basic cyano-containing anions $\left[\mathrm{N}(\mathrm{CN})_{2}{ }^{-}, \mathrm{C}(\mathrm{CN})_{3}{ }^{-}\right.$, and $\left.\mathrm{Au}(\mathrm{CN})_{2}{ }^{-}\right]$with $\mathrm{ZnX} 2\left(\mathrm{X}=\mathrm{Cl}^{-}, \mathrm{Br}^{-}\right.$, and $\mathrm{SCN}^{-}$) occurred during electrocrystallization. Based on the charge and arrangement of ET molecules, these salts were predominantly categorized into four groups: (A) isolated $\mathrm{ET}^{\bullet+}$ dimers or tetramers, $(\mathbf{B})$ infinite $\mathrm{ET}^{\bullet+}$ ribbon, $(\mathbf{C})$ infinite layers either with a peculiar $\mathrm{ET}^{0.5+}$ arrangement or of ET molecules with partial charges other than +0.5 , and $(\mathbf{D})$ infinite layers of $\mathrm{ET}^{0.5+}$ molecules. In $\mathbf{A}$, zinc(II) complex anions including a unidentate-coordinated $\mathrm{C}(\mathrm{CN})_{3}$ or $\mathrm{Au}(\mathrm{CN})_{2}$ group spatially interrupt the infinite arrangement of ET molecules. The $\mathrm{ET}^{\bullet+}$ ribbon in $\mathbf{B}$ runs parallel to the pseudo-polymeric chain of disordered $\mathrm{Zn}\left[\mathrm{C}(\mathrm{CN})_{3}\right]_{2} \mathrm{Br}_{2}{ }^{2-}$ ions. In $\mathbf{C}$, two salts are semiconductive, whereas the remaining two salts behave metallic at room temperature and undergo a metal-insulator transition on cooling. The ET molecules in D are arranged in a $\theta_{42+40}$-like packing motif, due to the non-planar anionic layers. All salts 
are semiconductive and exhibit a gradual evolution in their superstructures with cooling, associated with charge disproportionation.

Corresponding Author: Yukihiro Yoshida (Meijo University, Tel: +81-52-838-2552, Fax: +81-52-833-7200, E-mail: yyoshida@meijo-u.ac.jp) 


\section{BEDT-TTF Salts Formed with Tetrahedrally}

\section{Coordinated Zinc(II) Complex Anions}

Yukihiro Yoshida, ${ }^{* \dagger}$ Hiroshi Ito, ${ }^{\ddagger}$ Yuto Nakamura, ${ }^{\ddagger}$ Manabu Ishikawa, ${ }^{\S, \#}$ Akihiro Otsuka, ${ }^{\S, \#}$ Hiromi Hayama, ${ }^{\dagger}$ Mitsuhiko Maesato, ${ }^{\S}$ Hideki Yamochi, ${ }^{\S, \#}$ Hideo Kishida, ${ }^{\ddagger}$ and Gunzi Saito ${ }^{\dagger, \|}$

${ }^{\dagger}$ Faculty of Agriculture, Meijo University, Tempaku-ku, Nagoya 468-8502, Japan

‡ Department of Applied Physics, Nagoya University, Chikusa-ku, Nagoya 464-8603, Japan

$\S$ Division of Chemistry, Graduate School of Science, Kyoto University, Sakyo-ku, Kyoto 606-8502, Japan

\# Research Center for Low Temperature and Materials Sciences, Kyoto University, Sakyo-ku, Kyoto 606-8501, Japan

\| Toyota Physical and Chemical Research Institute, Nagakute 480-1192, Japan

Abstract: 12 kinds of bis(ethylenedithio)tetrathiafulvalene (BEDT-TTF or ET) cation salts with tetrahedrally coordinated zinc(II) complex anions were obtained by electrocrystallization; most of them were produced via the additional reaction of Lewis-basic cyano-containing anions $\left[\mathrm{N}(\mathrm{CN})_{2}{ }^{-}, \mathrm{C}(\mathrm{CN})_{3}{ }^{-}\right.$, and $\left.\mathrm{Au}(\mathrm{CN})_{2}{ }^{-}\right]$with $\mathrm{ZnX} 2\left(\mathrm{X}=\mathrm{Cl}^{-}, \mathrm{Br}^{-}\right.$, and $\mathrm{SCN}^{-}$) occurred during electrocrystallization. Based on the charge and arrangement of ET molecules, these salts were predominantly categorized into four groups: (A) isolated $\mathrm{ET}^{\bullet+}$ dimers or tetramers, $(\mathbf{B})$ infinite $\mathrm{ET}^{\bullet+}$ ribbon, $(\mathbf{C})$ infinite layers either with a peculiar $\mathrm{ET}^{0.5+}$ arrangement or of ET molecules with partial charges other than +0.5 , and (D) infinite layers of $\mathrm{ET}^{0.5+}$ molecules. In $\mathbf{A}$, zinc(II) complex anions including a unidentate-coordinated 
$\mathrm{C}(\mathrm{CN})_{3}$ or $\mathrm{Au}(\mathrm{CN})_{2}$ group spatially interrupt the infinite arrangement of ET molecules. The $\mathrm{ET}^{\bullet+}$ ribbon in $\mathbf{B}$ runs parallel to the pseudo-polymeric chain of disordered $\mathrm{Zn}\left[\mathrm{C}(\mathrm{CN})_{3}\right]_{2} \mathrm{Br}_{2}{ }^{2-}$ ions. In $\mathbf{C}$, two salts are semiconductive, whereas the remaining two salts behave metallic at room temperature and undergo a metal-insulator transition on cooling. The ET molecules in D are arranged in a $\theta_{42+40}$-like packing motif, due to the non-planar anionic layers. All salts are semiconductive and exhibit a gradual evolution in their superstructures with cooling, associated with charge disproportionation.

\section{Introduction}

Organic cation radical salts, which are primarily composed of electron donor molecules and inorganic anions, play a primary role in the exploration of molecular conductors. ${ }^{1-8}$ In these salts, anions not only serve to compensate the charge of the (partially) oxidized electron donors but also contribute to structural and physical properties of salts depending on the shape, size, and charge state of the anions. Bis(ethylenedithio)tetrathiafulvalene (BEDT-TTF or ET) cation radical salts are one of the most extensively studied and well-established families, primarily attributed to (i) the facile manner in which their single crystals are obtained, (ii) a wide variety of electronic properties, including antiferromagnetic (AF) insulators, quantum spin liquids, correlated metals, and unconventional superconductors closely associated to molecular packing manner, and (iii) a drastic change in the electronic properties associated with chemical or physical structural modification while maintaining the basic packing manner. In particular, planar polymeric anions involving a $\mathrm{d}^{10}$ metal ion $\mathrm{Cu}(\mathrm{I})$ and (pseudo)halide ligands such as $\left[\mathrm{Cu}(\mathrm{NCS})_{2}{ }^{-}\right]_{\infty},{ }^{9,10}\left\{\mathrm{Cu}\left[\mathrm{N}(\mathrm{CN})_{2}\right] \mathrm{X}^{-}\right\}_{\infty}\left(\mathrm{X}\right.$ : halides), ${ }^{11-16}$ and $\left[\mathrm{Cu}_{2}(\mathrm{CN})_{3}{ }^{-}\right]_{\infty}{ }^{17-19}$ have played a key role as counter anions in novel electronic materials. Recently, our group has reported some intriguing ET cation radical salts formed with planar polymeric anions involving another coinage metal ion $\mathrm{Ag}(\mathrm{I})$, such as $\left\{\mathrm{Ag}(\mathrm{CN})\left[\mathrm{N}(\mathrm{CN})_{2}\right]^{-}\right\}_{\infty}$ 
(weakly correlated ambient-pressure superconductor) ${ }^{20}$ and $\left[\mathrm{Ag}_{2}(\mathrm{CN})_{3}{ }^{-}\right]_{\infty}$ (quantum spin liquid at ambient pressure and superconductor under pressure). ${ }^{21,22}$ We now extend our material exploration to the ET salts combined with another $\mathrm{d}^{10}$ metal ion $\mathrm{Zn}(\mathrm{II})$. Thus far, ET salts formed with zinc(II) complex anions have been explored to a significantly lesser extent despite the fact that coordination bonds can be readily formed with zinc(II), affording new complex anions, attributed to the lability of zinc(II) species. ${ }^{23}$ To the best of our knowledge, zinc(II) complex anions combined with ET have been limited to discrete $\mathrm{ZnX}_{4}{ }^{2-}$ (X $=\mathrm{Cl}^{24,25}$ and $\mathrm{Br}^{26,27}$ ), dimeric $\mathrm{Zn}_{2}(\mathrm{SCN})_{6}{ }^{2-},{ }^{28,29}$ and one-dimensional (1D) polymeric [MZn(SCN $\left.)_{4}{ }^{-}\right]_{\infty}$ $(\mathrm{M}=\mathrm{Rb}, \mathrm{Cs}$, and $\mathrm{Tl}) .{ }^{28,30,31}$ Lewis basic monoanions $\left(\mathrm{Y}_{\mathrm{A}}{ }^{-}\right.$and $\left.\mathrm{Y}_{\mathrm{B}}{ }^{-}\right)$readily react with zinc(II) (pseudo)halides $\mathrm{ZnX}_{2}$ via nucleophilic addition, affording divalent $\mathrm{ZnX}_{2} \mathrm{Y}_{\mathrm{A}} \mathrm{Y}_{\mathrm{B}}{ }^{2-}$ ions in a hybrid $\mathrm{sp}^{3}$ state in anhydrous media, attributed to the Lewis acidity of $\mathrm{ZnX} \mathrm{X}_{2}$. We expect that, in contrast to the planar trigonal coordination for copper(I)- or silver(I)-containing polymeric anions, tetrahedral coordination results in a non-planar anionic surface, which would significantly affect the molecular arrangement in the ET layers.

In this study, 12 kinds of new ET cation salts, formed with zinc(II) complex anions coordinated by halides, (thio)cyano, and aqua groups, were obtained by the electrochemical oxidation of ET in the presence of $\mathrm{ZnX} 2\left(\mathrm{X}=\mathrm{Cl}^{-}, \mathrm{Br}^{-}\right.$, and $\left.\mathrm{SCN}^{-}\right)$. Typically, the following chemical reactions occur during electrocrystallization:

\section{$\underline{\text { Nucleophilic addition }}$}

$$
\mathrm{ZnX}_{2}+\mathrm{Y}_{\mathrm{A}}^{-}+\mathrm{Y}_{\mathrm{B}}^{-} \rightarrow \mathrm{ZnX}_{2} \mathrm{Y}_{\mathrm{A}} \mathrm{Y}_{\mathrm{B}}{ }^{2-}
$$

\section{Oxidation}

$$
x \mathrm{ET}+\mathrm{ZnX}_{2} \mathrm{Y}_{\mathrm{A}} \mathrm{Y}_{\mathrm{B}}{ }^{2-} \stackrel{-(2 / x) e}{\rightarrow}\left[\mathrm{ET}^{(2 / x)+}\right]_{x}\left(\mathrm{ZnX}_{2} \mathrm{Y}_{\mathrm{A}} \mathrm{Y}_{\mathrm{B}}{ }^{2-}\right)
$$


Cyano-containing zinc(II) complex anions produced during the process include monomeric $\mathrm{Zn}\left[\mathrm{C}(\mathrm{CN})_{3}\right] \mathrm{X}_{3}{ }^{2-}[\mathrm{X}=\mathrm{Cl}(\mathbf{1})$ and $\mathrm{Br}(2,7)], \mathrm{Zn}\left[\mathrm{Au}(\mathrm{CN})_{2}\right] \mathrm{X}_{3}{ }^{2-}[\mathrm{X}=\mathrm{Cl}$ (3) and $\mathrm{Br}(4)]$, $\mathrm{Zn}\left[\mathrm{C}(\mathrm{CN})_{3}\right]_{2} \mathrm{Br}_{2}{ }^{2-}(\mathbf{5}), \mathrm{Zn}(\mathrm{NCS})_{2} \mathrm{X}_{2}{ }^{2-}[\mathrm{X}=\mathrm{Cl}(\mathbf{1 0})$ and $\mathrm{Br}(\mathbf{1 1})], \mathrm{Zn}\left[\mathrm{N}(\mathrm{CN})_{2}\right] \mathrm{Cl}_{3}{ }^{2-}$ (12) and polymeric $\left\{\mathrm{Zn}\left[\mathrm{N}(\mathrm{CN})_{2}\right] \mathrm{Cl}_{2}{ }^{-}\right\}_{\infty}(\mathbf{6})$. Figure 1 shows the molecular structures of $\mathrm{Zn}(\mathrm{NCS})_{2} \mathrm{Cl}_{2}{ }^{2-}$, $\mathrm{Zn}\left[\mathrm{N}(\mathrm{CN})_{2}\right] \mathrm{Cl}_{3}{ }^{2-}, \mathrm{Zn}\left[\mathrm{C}(\mathrm{CN})_{3}\right] \mathrm{Cl}_{3}{ }^{2-}$, and $\mathrm{Zn}\left[\mathrm{Au}(\mathrm{CN})_{2}\right] \mathrm{Cl}_{3}{ }^{2-}$, which were crystallographically characterized herein. Zinc(II) ions in these anions are tetrahedrally coordinated by nitrile nitrogen(s), in addition to halides; namely, the $\mathrm{NCS}^{-}, \mathrm{N}(\mathrm{CN})_{2}{ }^{-}, \mathrm{C}(\mathrm{CN}) 3^{-}$, and $\mathrm{Au}(\mathrm{CN}) 2^{-}$ groups in monomeric anions (1-5, 7, and 10-12) serve as unidentate ligands, whereas the $\mathrm{N}(\mathrm{CN})_{2}{ }^{-}$group in polymeric anion (6) serves as a $\mu_{1,5}$-bidentate bridging ligand, affording the 1D polymeric $\left\{\mathrm{Zn}\left[\mathrm{N}(\mathrm{CN})_{2}\right] \mathrm{Cl}_{2}{ }^{-}\right\}_{\infty}$ ions. In addition, new ET salts were obtained by combining with zinc(II) halides, i.e. $\mathrm{ZnCl}_{3}\left(\mathrm{H}_{2} \mathrm{O}\right)^{-}(\mathbf{8})$ and $\mathrm{ZnBr}_{4}{ }^{2-}$ (9). Their unique molecular arrangement derived from the tetrahedral coordination of zinc(II), as well as structure-property relationship, with focus on intermolecular interactions and charge states on ET molecules is discussed.

$* * * * * * * * * *$ Figure 1

\section{Results and Discussion}

\subsection{Electrocrystallization}

All salts were obtained by the electrochemical oxidation of ET (see Experimental section for details), and the synthetic conditions such as reagents and solvents used are summarized in Table 1. Typically, ET was added to an anodic compartment, while the other reagents were added to the cathodic compartment of an H-shaped glass cell, which was assembled in a glove box filled with argon gas $\left(\mathrm{H}_{2} \mathrm{O}, \mathrm{O}_{2}<1 \mathrm{ppm}\right)$. After being stirred in a solvent such as 1,1,2-trichloroethane (TCE) or a TCE/alcohol mixture at room temperature (RT), a constant 
current $(1.0 \mu \mathrm{A})$ was passed between the two platinum electrodes over approximately two weeks at a constant temperature ( 15 or $\left.20^{\circ} \mathrm{C}\right)$. Several phases were simultaneously harvested, which were separated under a microscope and identified by X-ray diffraction measurements. At present, the formation of zinc(II) complex anions including other cyano-containing groups such as $\mathrm{Ag}(\mathrm{CN})_{2}^{-}$or $\mathrm{B}(\mathrm{CN})_{4}^{-}$has not been successful.

$* * * * * * * * * *$ Table 1

The crystallographic data of $\mathbf{1 - 1 2}$ are summarized in Table 2. Crystal structures of the salts, except for 8, were determined at $100 \mathrm{~K}$. Although salt 8 undergoes a metal-insulator transition, accompanied by the symmetry reduction (from $P 2_{1} / n$ to $P 2_{1}$ ) at $210 \mathrm{~K}$, structural refinement at $100 \mathrm{~K}$ was not sufficient, possibly due to incomplete phase transition. In addition, crystallographic studies at $298 \mathrm{~K}$ were performed for $\mathbf{4}$ and $\mathbf{8}-\mathbf{1 2}$, because they exhibit a sign of a structural or electronic phase transition below RT. In the following section, we will describe the structural and physical properties of the salts in four groups: isolated $\mathrm{ET}^{\bullet+}$ dimers or tetramers (Group A), infinite $\mathrm{ET}^{\bullet+}$ ribbon (Group B), infinite layers either with a peculiar $\mathrm{ET}^{0.5+}$ arrangement or of ET molecules with partial charges other than +0.5 (Group C), and infinite layers of $\mathrm{ET}^{0.5+}$ molecules (Group D).

*********** Table $2 * * * * * * * * * *$

\subsection{Group A}

2.2.1 (ET) ${ }_{2} \mathbf{Z n}\left[\mathbf{C}(\mathbf{C N})_{3}\right] \mathbf{C l}_{3}$ (1): Salt $\mathbf{1}$ crystallizes in a monoclinic lattice with space group $P 2_{1} / C$ at $100 \mathrm{~K}$, and the asymmetric unit contains two ET molecules (A and $\mathbf{B}$ ) and one $\mathrm{Zn}\left[\mathrm{C}(\mathrm{CN})_{3}\right] \mathrm{Cl}_{3}{ }^{2-}$ ion (Fig. 1c). This composition indicates the completely oxidized ET 
molecules; however, ET molecules appear to be charge-disproportionated on the basis of bond distance analysis $(+0.72(4)$ for $\mathbf{A}$ and $+1.07(4)$ for $\mathbf{B}) .{ }^{32}$ This salt has a layered structure within the $a b$ plane (Fig. 2a). In the layer, ET molecules are arranged along the $2 a+b$ direction, affording a tetrameric subunit with a BAAB arrangement pattern (Fig. 2b), separated by a pair of $\mathrm{Zn}\left[\mathrm{C}(\mathrm{CN})_{3}\right] \mathrm{Cl}_{3}{ }^{2-}$. In a tetramer located on an inversion center, inner (A) and outer ET (B) molecules appear to be charge-poor and charge-rich, respectively, and the tetramer composed of the two A-B pairs possibly has +4 charge. Overlap integrals between the HOMOs of ET molecules within the tetramer were calculated on the basis of the extended Hückel method, ${ }^{33}$ where $\mathrm{p} 1=-28.2 \times 10^{-3}$ for an $\mathbf{A}-\mathbf{B}$ pair with a ring-over-bond-type overlap (Fig. 2c) and $\mathrm{p} 2=-4.8 \times 10^{-3}$ for an $\mathbf{A}-\mathbf{A}$ pair with a ring-over-atom overlap (Fig. 2d).

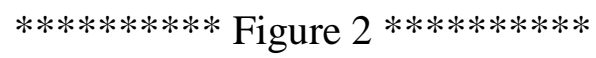

In $\mathrm{Zn}\left[\mathrm{C}(\mathrm{CN})_{3}\right] \mathrm{Cl}_{3}{ }^{2-}$ ion, a unidentate-coordinated $\mathrm{C}(\mathrm{CN})_{3}$ moiety exhibits an almost flat geometry, as can be seen in Fig. 1c, which penetrates the ET layer. Such a penetration of a part of anions has been observed for several ET salts. ${ }^{34-38}$ Each $\mathrm{C}(\mathrm{CN})_{3}$ moiety approaches another $\mathrm{C}(\mathrm{CN})_{3}$ moiety from the other side, related by an inversion center, and lies in the same plane. On the other hand, the sterically bulky $\mathrm{ZnCl}_{3}$ moiety remains outside the ET layer and connects with four ET molecules in the adjacent layer through S $\cdots \mathrm{Cl}(3.41 \AA$ vs. sum of the van der Waals radii: $\left.3.55 \AA^{39}\right)$ and $\mathrm{C}-\mathrm{H} \cdots \mathrm{Cl}(2.71-2.94 \AA$ vs. sum of the van der Waals radii: $2.95 \AA^{39}$ ) interactions.

2.2.2 (ET) $)_{2} \mathrm{Zn}\left[\mathrm{C}(\mathrm{CN})_{3}\right] \mathrm{Br}_{3}$ (2): In this study, three kinds of ET salts were obtained by combining with zinc(II) complex anions including bromides and unidentate-coordinated 
$\mathrm{C}(\mathrm{CN})_{3}$ group(s) $(2,5$, and 7). In most cases, these crystals were simultaneously grown but readily separated by the difference in their shape.

Salt 2 belongs to the monoclinic system with space group $P 2_{1} / n$ at $100 \mathrm{~K}$. Two ET molecules (A and $\mathbf{B}$ ) and one $\mathrm{Zn}\left[\mathrm{C}(\mathrm{CN})_{3}\right] \mathrm{Br}_{3}{ }^{2-}$ ion are crystallographically independent. The anionic structure and composition are identical with those of $\mathbf{1}$. Within the $a b$ plane (Fig. 3a), ET molecules are aligned along the $2 a+b$ direction, affording a BAAB-type tetrameric subunit as a part of $\beta^{\text {' }}$-type infinite stacking (Fig. 3b) ${ }^{40}$ unlike the case in $\mathbf{1}$, which is separated by a pair of $\mathrm{Zn}\left[\mathrm{C}(\mathrm{CN})_{3}\right] \mathrm{Br}_{3}{ }^{2-}$. Bond distance analysis estimates the charges of $\mathrm{ET}$ molecules to be +0.69 (4) for $\mathbf{A}$ and $+1.09(4)$ for $\mathbf{B} ;^{32}$ namely, the tetramer composed of the two A-B pairs possibly has +4 charge as expected from the composition. Overlap integrals between ET molecules within the tetramer were calculated to be p1 $=-29.0 \times 10^{-3}$ for an $\mathbf{A}-$ $\mathbf{B}$ pair with a ring-over-bond-type overlap (Fig. 3c) and p2 $=-0.2 \times 10^{-3}$ for an A-A pair with a ring-over-atom overlap (Fig. 3d).

Figure 3

$\mathrm{Zn}\left[\mathrm{C}(\mathrm{CN})_{3}\right] \mathrm{Br}_{3}{ }^{2-}$ ion includes an almost flat $\mathrm{C}(\mathrm{CN})_{3}$ moiety as a unidentate ligand, which penetrates the ET layer as in the case of $\mathbf{1}$. Each $\mathrm{C}(\mathrm{CN})_{3}$ moiety approaches another $\mathrm{C}(\mathrm{CN})_{3}$ moiety from the other side, related by an inversion center, and is present in the same plane. On the other hand, the sterically bulky $\mathrm{ZnBr}_{3}$ moiety remains outside the ET layer and connects with four ET molecules in the adjacent layer through the S $\cdots \mathrm{Br}$ (3.44 $\AA$ vs. sum of the van der Waals radii: $\left.3.65 \AA^{39}\right)$ and $\mathrm{C}-\mathrm{H} \cdots \mathrm{Br}(2.86-2.98 \AA$ vs. sum of the van der Waals radii: $3.05 \AA^{39}$ ) interactions.

2.2.3 (ET) ${ }_{2} \mathrm{Zn}\left[\mathrm{Au}(\mathrm{CN})_{2}\right] \mathrm{Cl}_{3}(3)$ and $(\mathrm{ET})_{2} \mathrm{Zn}\left[\mathrm{Au}(\mathrm{CN})_{2}\right] \mathrm{Br}_{3}(\mathrm{EtOH})_{0.5}(4)$ : Salt 3 crystallizes 
in the monoclinic system with space group $P 2{ }_{1} / c$ at $100 \mathrm{~K}$, and an asymmetric unit contains two ET molecules and one $\mathrm{Zn}\left[\mathrm{Au}(\mathrm{CN})_{2}\right] \mathrm{Cl}_{3}{ }^{2-}$ ion. The composition results in a nominal charge of +1 on each ET, which was confirmed by the estimation of the charge of the ET molecules on the basis of bond distance analysis $(+0.99(3)$ and $+0.91(3)) .{ }^{32}$ As illustrated in Fig. 4a, ET molecules are assembled in a two-dimensional (2D) layer within the $b c$ plane. Two crystallographically independent ET molecules form a face-to-face twisted dimer with a torsion angle around the central $\mathrm{C}=\mathrm{C}$ bonds of $10.0^{\circ}$ (Fig. $4 \mathrm{~b}$; called as $\alpha$ - or $\delta$-type; ${ }^{41}$ the former involves the ET molecules twisted relative to the adjacent molecules along the stacking direction, whereas the latter involves the parallel ET dimers twisted relative to the adjacent dimers along the stacking direction), through $S \cdots S$ heteroatomic contacts (3.38-3.59 $\AA$ vs. sum of the van der Waals radii: $3.60 \AA^{39}$ ) and $\mathrm{C}-\mathrm{H} \cdots \mathrm{S}$ hydrogen bonds ( $\mathrm{H} \cdots \mathrm{S}$ distance: 2.91-2.97 $\AA$ vs. sum of the van der Waals radii: $3.00 \AA^{39}$ ). In fact, the intra-dimer overlap integral between ET molecules ( $\mathrm{b} 1=41.4 \times 10^{-3}$ ) is significantly greater than the inter-dimer ones $\left(<21.4 \times 10^{-3}\right)$. Each dimer is almost perpendicular to the adjacent dimer along the $c$ axis; namely, the $\kappa$-like packing motif (orthogonal arrangement of face-to-face ET dimers) based on diamagnetic (ET) ${ }^{2+}$ dimers (Fig. 4c). ${ }^{42}$

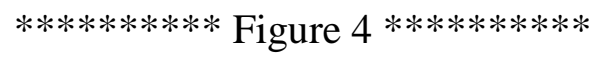

As can be seen in Figs. 1d and 4a, each $\mathrm{Au}(\mathrm{CN})_{2}$ moiety has an almost linear geometry $(\mathrm{C}-$ $\left.\mathrm{Au}-\mathrm{C}: 178.60(9)^{\circ}\right)$ and penetrates the ET layer inclined at approximately $16^{\circ}$ with respect to the $a$ axis, where half of them are aligned along the $+a$ direction, while the remaining half run along the $-a$ direction. Within the ET layer, the terminal cyano group of $\mathrm{Au}(\mathrm{CN})_{2}$ moieties interacts with two neighboring ET molecules through $\mathrm{C} \equiv \mathrm{N} \cdots \pi(\mathrm{C} 21 \cdots \mathrm{C} 11: 3.36 \AA$, $\mathrm{N} 1 \cdots \mathrm{C} 12: 3.13 \AA)^{43}$ and $\mathrm{S} \cdots \mathrm{N}\left(3.26-3.34 \AA\right.$ vs. sum of the van der Waals radii: $\left.3.35 \AA^{39}\right)$ 
contacts. Three chlorides are connected with six ET molecules, including three in the layer and three in the adjacent layer, through $\mathrm{S} \cdots \mathrm{Cl}(3.22-3.48 \AA)$ and $\mathrm{C}-\mathrm{H} \cdots \mathrm{Cl}(2.73-2.94 \AA)$ contacts.

Here, the structural geometry of ET molecules is discussed on the basis of the inter-dimer interactions for comparison with related ET salts. The transfer integral $(t)$ along the $c$ axis $\left(t_{1}\right.$ $=\left|t_{\mathrm{c}}\right| / 2=73.5 \mathrm{meV}$ ), estimated on the basis of the assumption $t=E s$ (s: overlap integral, $E=$ $-10 \mathrm{eV})$, is comparable to that along the $b$ axis $\left(t_{\mathrm{b} 2} / 2=107 \mathrm{meV}\right.$ and $\left(2\left|t_{\mathrm{b} 3}\right|+\left|t_{\mathrm{b} 4}\right|\right) / 2=85.6$ meV result in an average value $t_{2}=96.3 \mathrm{meV}$ ). On the other hand, the transfer integral along the oblique direction $\left(t_{3}=\left(\left|t_{\mathrm{p}}\right|+\left|t_{\mathrm{q}}\right|\right) / 2=1.7 \mathrm{meV}\right)$ is significantly smaller relative to them, mainly due to the spatial interruption of the $\mathrm{Zn}\left[\mathrm{Au}(\mathrm{CN})_{2}\right] \mathrm{Cl}_{3}{ }^{2-}$ ions (right panel in Fig. $4 \mathrm{c}$ ). As a result, these values provide the anisotropy of an isosceles triangular lattice $t_{3} /\left[\left(t_{1}+t_{2}\right) / 2\right]$ $=0.02$. Therefore, the $\kappa$-like arrangement in $\mathbf{3}$ can be regarded as a square lattice as in the case of $\beta$ '-(ET) $)_{2} \mathrm{X}$ salts $\left(0.16\right.$ for $\mathrm{X}=\mathrm{ICl}_{2}$ and 0.19 for $\left.\mathrm{X}=\mathrm{AuCl}_{2}\right){ }^{40}$ whereas the $\kappa$-(ET) $)_{2} \mathrm{X}$ salts based on spin-1/2 (ET) $2^{\bullet+}$ dimers exhibits more or less triangular form. ${ }^{1-8,42}$ The present assembly possibly provides an important clue for the preferential production of ET cation radical salts with the square spin lattice, although the $(\mathrm{ET})_{2}{ }^{2+}$ dimers in $\mathbf{3}$ are diamagnetic. Notably, among the ET family, the $\beta^{\prime}-(\mathrm{ET})_{2} \mathrm{X}$ salts based on spin-1/2 $(\mathrm{ET})_{2}{ }^{\bullet+}$ dimers are a typical strongly correlated system, and indeed, some of them exhibit long-range AF ordering and superconductivity under applied pressures. ${ }^{44,45}$

Salt 4 appears to exhibit some similarities with $\mathbf{3}$, in addition to striking differences. The molecular arrangement is very similar to that of $\mathbf{3}$, but the space group at low temperature is different (monoclinic $P 2{ }_{1} / c$ at $298 \mathrm{~K}$ and triclinic $P \overline{1}$ at $100 \mathrm{~K}$ ). In addition, salt 4 includes orientationally disordered EtOH molecules on an inversion center between the ET layers. Within the dimer, an ET molecule slides with respect to another molecule along the molecular long axis by $1.3 \AA$ (Fig. 4d) and $0.8 \AA$ (Fig. 4e) for two crystallographically independent 
dimers. Such overlap patterns are reminiscent of those in monocationic salts, $(E T)_{2} \mathrm{M}_{6} \mathrm{O}_{19}(\mathrm{M}$ $=\mathrm{Mo}^{\mathrm{VI}}$ and $\left.\mathrm{W}^{\mathrm{VI}}\right)^{46}$ and $(\mathrm{ET})_{2} \mathrm{Pd}(\mathrm{dto})_{2}\left(\mathrm{H}_{2} \text { dto: dithiooxalic acid }\right)^{47}$ with similar molecular arrangements. Transfer integrals between $(\mathrm{ET})_{2}{ }^{2+}$ dimers, $t_{1}=74.6 \mathrm{meV}, t_{2}=94.8 \mathrm{meV}$, and $t_{3}$ $=3.4 \mathrm{meV}$, result in the anisotropy of an isosceles triangular lattice $t_{3} /\left[\left(t_{1}+t_{2}\right) / 2\right]=0.04$, which is also less than those of $\beta$ '-(ET) $)_{2} .^{40}$

\subsection{Group B}

2.3.1 (ET) ${ }_{2} \mathrm{Zn}\left[\mathrm{C}(\mathbf{C N})_{3}\right]_{2} \mathrm{Br}_{2}$ (5): The isostructural chloride salt $(\mathrm{ET})_{2} \mathrm{Zn}\left[\mathrm{C}(\mathrm{CN})_{3}\right]_{2} \mathrm{Cl}_{2}$ was obtained as a by-product of $\mathbf{1}$. However, structural refinement is not sufficient to discuss the structural features in detail, due to its inferior crystallinity $\left(R_{1} \sim 0.08\right)$; hence, the bromide salt 5 is focused in this paper.

Salt 5 is triclinic with space group $P \overline{1}$, and an asymmetric unit contains one ET molecule and half $\mathrm{Zn}\left[\mathrm{C}(\mathrm{CN})_{3}\right]_{2} \mathrm{Br}_{2}{ }^{2-}$ ion (Fig. 5a). In the crystal, ET molecules form a $1 \mathrm{D}$ array through short S $\cdots$ S heteroatomic contacts (3.42-3.56 $\AA$ ) along the side-by-side direction or the crystallographic $a$ axis (Fig. 5b). The two parallel ET arrays are connected to each other, affording an infinite double array centered at $z=0.5$ (Fig. 5c). On the basis of intramolecular bond lengths, ${ }^{32}$ the charge of the ET molecule was estimated to be $+0.78(7)$, deviated from a nominal charge of +1 . However, the salt exhibits semiconducting behavior with a RT conductivity $\left(\sigma_{\mathrm{RT}}\right)$ of $1.2 \mathrm{~S} \mathrm{~cm}^{-1}$ and an activation energy ( $\left.E_{\mathrm{a}}\right)$ of $0.078 \mathrm{eV}$ (Fig. 6a), supporting the fully ionic state of ET. The optical absorption spectrum exhibits no remarkable band below $5 \times 10^{3} \mathrm{~cm}^{-1}$ attributed to the partially oxidized state. ${ }^{6}$

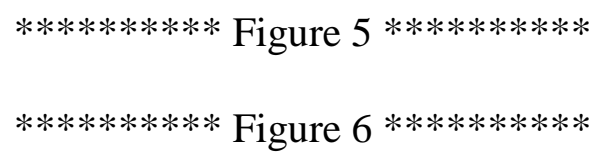


Each $\mathrm{Zn}\left[\mathrm{C}(\mathrm{CN})_{3}\right]_{2} \mathrm{Br}_{2}{ }^{2-}$ ion is positionally disordered over two sites with an equivalent occupancy of 0.5 , resulting in the formation of a pseudo-polymeric chain in parallel to the ET arrays along the $a$ axis. Each zinc(II) ion is tetrahedrally coordinated by two $\mathrm{C}(\mathrm{CN})_{3}$ groups and two bromides, and the average structure with respect to disorder is regarded such that these ligands serve as a bidentate bridging ligand to link zinc(II) ions between adjacent zinc 'pseudo-dimers' (Fig. 5d). Notably, bromides, protruding toward the ET layers on both sides, are located at the vacancy sites in the ET layers, as shown in Fig. 5e; namely, the geometry of the pseudo-polymeric chain of $\mathrm{Zn}\left[\mathrm{C}(\mathrm{CN})_{3}\right]_{2} \mathrm{Br}_{2}{ }^{2-}$ ions significantly affects the packing motif in ET layers.

Based on the extended Hückel calculations, ${ }^{33}$ transfer integrals within the double array were determined as $t_{\mathrm{a}}=216, t_{\mathrm{p}}=54.9$, and $t_{\mathrm{q}}=62.2 \mathrm{meV}$; therefore, the $\mathrm{ET}^{\bullet+}$ array is regarded as a zig-zag chain with a greater interaction along the chain direction (Fig. 5b). Recently, 1D triangle-based materials composed of corner-sharing-triangular (or $\Delta$-chain; Fig. 6b), sawtooth (Fig. 6c), ${ }^{48}$ zig-zag (Fig. 6d), ${ }^{49,50}$ diamond (Fig. 6e), ${ }^{51,52}$ or orthogonal-dimer (Fig. 6f $)^{53}$ chains are attracting considerable attention as potentially benign spin-frustrated systems, apart from 2D (e.g. triangular and kagome) and 3D (e.g. hyperkagome) ones. In the zig-zag chain system, the ratio $J^{\prime} / J$, where $J$ and $J^{\prime}$ represent the nearest- and next-nearest-neighbor exchange interactions, is a measure of spin frustration. A theoretical study has predicted that the $S=1 / 2$ zig-zag chain has a collinear gapless phase for $J ' / J<$ $0.241,{ }^{49,50}$ as suggested for $\mathrm{Cu}^{\mathrm{II}}[2$-(2-aminomethyl)pyridine $] \mathrm{Br}_{2}\left(J^{\prime} / J=0.2, J / k_{\mathrm{B}}=8.5 \mathrm{~K}\right)^{54,55}$ and $\left(\mathrm{V}^{\mathrm{IV}} \mathrm{O}\right)\left(\mu_{3}-\mathrm{MoO}_{4}\right)\left(2,2^{\prime}\right.$-bipyridine $)\left(J^{\prime} / J=0.2, J / k_{\mathrm{B}}=51 \mathrm{~K}\right) .^{56,57}$

Figure 6a shows the temperature dependence of static magnetic susceptibility $(\chi)$ of the polycrystalline sample. As the $J^{\prime} / J$ value (0.073) expressed as $\left[\left(\left|t_{\mathrm{p}}\right|+\left|t_{\mathrm{q}}\right|\right) / 2\left|t_{\mathrm{a}}\right|\right]^{2}$ is apparently less than the critical value, the $S=1 / 2$ Heisenberg AF linear chain studied by Bonner and Fisher $\left(\chi_{\mathrm{BF}}\right)^{58,59}$ is utilized, indicative of a uniform $\mathrm{ET}^{\bullet+}$ chain with negligible interchain 
interactions. The $\chi$ value can be numerically fitted by the sum of $\chi_{\mathrm{BF}}$ and a Curie component $\left(\chi_{\mathrm{C}}\right)$ with a fraction $f$ as follows;

$$
\begin{aligned}
& \chi=f \chi_{\mathrm{BF}}+(1-f) \chi_{\mathrm{C}} \\
& \chi_{\mathrm{BF}}=\frac{N g^{2} \mu_{\mathrm{B}}^{2}}{k_{\mathrm{B}} T} \frac{A+B x+C x^{2}}{1+D x+E x^{2}+F x^{3}} \quad\left(x=J / k_{\mathrm{B}} T\right) \\
& \chi_{\mathrm{C}}=C^{\prime} / T
\end{aligned}
$$

( $N$ : Avogadro number, $g$ : Landé $g$-factor, $\mu_{\mathrm{B}}$ : Bohr magneton, $k_{\mathrm{B}}$ : Boltzmann constant, $C^{\prime}$ : Curie constant). In the case of an equally spaced spin chain, coefficients are given by $A=$ 0.25, $B=0.14995, C=0.30094, D=1.98654, E=0.68854$, and $F=6.0626$. The best-fitted parameters are $J / k_{\mathrm{B}}=250 \mathrm{~K}$ and $C^{\prime}=3 \times 10^{-3}$ emu $\mathrm{K} \mathrm{mol}^{-1}$ and the former is expected to be well tuned by the replacement of the protruded bromides with other halides.

\subsection{Group C}

2.4.1 (ET) $2 \mathrm{Zn}\left[\mathbf{N}(\mathrm{CN})_{2}\right]_{\mathrm{Cl}_{2}}(\mathrm{TCE})_{0.5}$ (6): Salt 6 was obtained by electrocrystallization under the same conditions as those utilized for $\mathbf{1 2}$, and has a crystal symmetry (triclinic $P \overline{1}$ ) less than that of 12. Crystallographically independent unit contains one full (A) and two half (B and $\mathbf{C}$ ) ET, one $\mathrm{Zn}\left[\mathrm{N}(\mathrm{CN})_{2}\right] \mathrm{Cl}_{2}^{-}$unit, and half TCE. As can be seen in Fig. 7a, ET molecules form a layered structure within the $a b$ plane at $z \sim 0$, in which parallel and coplanar adjacent molecules exist along the side-by-side direction ( $a$ axis) for each molecule. In the layers, $\mathbf{A}$ is located at a general position, whereas $\mathbf{B}$ and $\mathbf{C}$ are located on an inversion center. $\mathbf{A}$ and $\mathbf{B}$ form a domain of parallel-oriented ET molecules, which is separated by $\mathbf{C}$ twisted with respect to $\mathbf{A}$, with a torsion angle of $31.0^{\circ}$ around the central $\mathrm{C}=\mathrm{C}$ bond. Such a twisted structure reminds us of the $\alpha$ - and $\delta$-type packing pattern. ${ }^{41}$ To our best knowledge, salt 6 has 
an unprecedented packing pattern of ET molecules. The charges of $\mathbf{A}, \mathbf{B}$, and $\mathbf{C}$ were estimated to be $+0.36(8)$, $+0.82(10)$, and $+0.83(11)$, respectively, strongly implying the presence of charge disproportionation. The charge-poor (A) and charge-rich (B or C) ET molecules are alternately arranged along the $b$ axis, i.e. each of charge-poor or charge-rich ET molecules are arranged along the $a$ axis (horizontal stripe). ${ }^{60,61}$

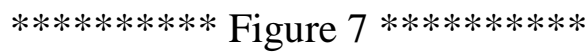

Within the $a b$ plane at $z \sim 0.5$, two chlorides and two $\mathrm{N}(\mathrm{CN})_{2}{ }^{-}$coordinate to zinc(II) ion, and the $\mathrm{N}(\mathrm{CN})_{2}^{-}$ligands serve as a $\mu_{1,5}$-bidentate bridging ligand to link the adjacent zinc(II) ions, resulting in a polymeric anionic chain running along the $a$ axis (Fig. 7b). Notably, the coordination environment in $\left\{\mathrm{Zn}\left[\mathrm{N}(\mathrm{CN})_{2}\right] \mathrm{Cl}_{2}^{-}\right\}_{\infty}$ (Fig. 7c) is entirely different from that in $\left\{\mathrm{Cu}\left[\mathrm{N}(\mathrm{CN})_{2}\right] \mathrm{X}^{-}\right\}_{\infty} \quad(\mathrm{X}: \quad$ halides; $\quad$ Fig. $\quad 7 d) \quad$ in well-known superconductors $\kappa$-(ET) $)_{2} \mathrm{Cu}\left[\mathrm{N}(\mathrm{CN})_{2}\right] \mathrm{X},{ }^{11-16}$ in which copper(I) is trigonally coordinated to one halide and two $\mathrm{N}(\mathrm{CN})_{2}$ groups through a nitrile nitrogen. Besides the coordination number to central metal ions, different orientations of $\mathrm{N}(\mathrm{CN})_{2}{ }^{-}$, i.e. 'in-phase' orientation for $\left\{\mathrm{Zn}\left[\mathrm{N}(\mathrm{CN})_{2}\right] \mathrm{Cl}_{2}{ }^{-}\right\}_{\infty}$ and 'out-of-phase' orientation for $\left\{\mathrm{Cu}\left[\mathrm{N}(\mathrm{CN})_{2}\right] \mathrm{X}^{-}\right\}_{\infty}$ were observed. The assembly of the polymeric chains affords an anionic layer within the $a b$ plane, in which disordered TCE molecules are accommodated in the cavities formed between the polymers.

As shown in Fig. 7e, charge-rich $\mathbf{B}$ and $\mathbf{C}$ are located near the $\left\{\mathrm{Zn}\left[\mathrm{N}(\mathrm{CN})_{2}\right] \mathrm{Cl}_{2}^{-}\right\}_{\infty}$ chains through the S $\cdots \mathrm{Cl}(3.31 \AA)$ and $\mathrm{C}-\mathrm{H} \cdots \mathrm{Cl}(2.72-2.94 \AA)$ interactions for $\mathbf{B}$ and the $\mathrm{S} \cdots \mathrm{Cl}$ (3.46 $\AA$ ) and $\mathrm{C}-\mathrm{H} \cdots \mathrm{Cl}(2.71 \AA)$ interactions for $\mathbf{C}$. Thus, the intermolecular Coulomb interactions are most likely a dominant factor for determining the pattern of charge disproportionation in $\mathbf{6}$.

The salt exhibits semiconducting behavior with $\sigma_{\mathrm{RT}}=0.4 \mathrm{~S} \mathrm{~cm}^{-1}$ and $E_{\mathrm{a}}=0.074 \mathrm{eV}$ (Fig. 
8a), mainly because of the charge-disproportionated state. Figure 8b shows the temperature dependence of $\chi$ of the polycrystalline sample. The $\chi$ value is $9.0 \times 10^{-4} \mathrm{emu} \mathrm{mol}^{-1}$ at $\mathrm{RT}$, which exceeds that for typical organic metals $\left(3-5 \times 10^{-4} \mathrm{emu} \mathrm{mol}^{-1}\right) .{ }^{6}$ It gradually increases with decreasing temperature and exhibits a rounded maximum at around $20 \mathrm{~K}$, attributed to AF fluctuation. Notably, in the whole temperature range, the $\chi$ value (50-60\% of free spin) is significantly less than those expected from the $S=1 / 2$ Heisenberg AF linear chain ${ }^{58,59}$ with $J / k_{\mathrm{B}}=15 \mathrm{~K}$ (Eq. $\left.1^{\prime}\right)$ and square lattice ${ }^{62}$ with $J / k_{\mathrm{B}}=10 \mathrm{~K}$. Although the factors that suppress the magnetic moments remain very unclear, the present results may indicate the dimerization of some charge-rich ET molecules along the side-by-side direction (// $a$ axis) that cannot be detected by X-ray diffraction measurements. An upturn below the temperature appears to be attributed to crystal defect, Curie impurity, and/or isolated $(\mathrm{ET})_{\mathrm{x}}{ }^{\bullet+}$ species. The localized nature apparently conflicts with the band structure calculated by assuming uniform charge distribution in the ET layer (i.e. +0.50 e on each ET), which shows the finite density of states (DOS) at the Fermi level (Fig. S1 in in Supporting Information). It is possible that this discrepancy arises from the occurrence of charge disproportionation as mentioned above.

$* * * * * * * * * *$ Figure $8 * * * * * * * * * *$

2.4.2 (ET) ${ }_{5}\left\{\mathbf{Z n}\left[\mathbf{C}(\mathbf{C N})_{3}\right] \mathbf{B r}_{3}\right\}_{2}$ (7): Salt 7 has a lower crystal symmetry (triclinic $P \overline{1}$ ) than that of 2, and includes ET and $\mathrm{Zn}\left[\mathrm{C}(\mathrm{CN})_{3}\right] \mathrm{Br}_{3}{ }^{2-}$ in a ratio of 5:2; namely, the ET molecules have a nominal charge of +0.8 . The asymmetric unit contains four full $(\mathbf{A}, \mathbf{C}, \mathbf{E}$, and $\mathbf{F})$ and two half (B and $\mathbf{D})$ ET molecules and two $\mathrm{Zn}\left[\mathrm{C}(\mathrm{CN})_{3}\right] \mathrm{Br}_{3}{ }^{2-}$ ions. In the crystal, two kinds of ET layers (Layer-1 and Layer-2; Fig. 9a) are present, both of which are expanded within the $a b$ plane. Layer- 1 at $z \sim 0$ consists only of ET molecules, which are arranged in a $\theta_{31}$-like packing motif (Fig. 9b). ${ }^{42}$ The charges of ET molecules (A-D) were estimated to be 
$+0.12(10),+0.39(9),+0.72(13)$, and $+0.69(12)$, respectively, on the basis of bond distance analysis; ${ }^{32}$ these values strongly indicate the presence of charge disproportionation with a vertical stripe pattern, ${ }^{60,61}$ in which each of charge-poor or charge-rich ET molecules are arranged along the $b$ axis and the total charge in the unit lattice is $+2.76(28)$. Reflecting the charge-disproportionated state, the salt also exhibits semiconducting behavior with $\sigma_{\mathrm{RT}}=1.1$ $\times 10^{-3} \mathrm{~S} \mathrm{~cm}^{-1}$ and $E_{\mathrm{a}}=0.225 \mathrm{eV}$ (Fig. 8a).

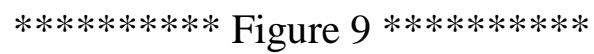

In Layer-2 at $z \sim 0.5$, on the other hand, $\mathrm{ET}$ and $\mathrm{Zn}\left[\mathrm{C}(\mathrm{CN})_{3}\right] \mathrm{Br}_{3}{ }^{2-}$ are included in equimolar amounts, and only the $\mathrm{C}(\mathrm{CN})_{3}$ moieties of $\mathrm{Zn}\left[\mathrm{C}(\mathrm{CN})_{3}\right] \mathrm{Br}_{3}{ }^{2-}$ ions penetrate the layer (Fig. 9c) as in the case of $\mathbf{2}$. However, the $\mathrm{C}(\mathrm{CN})_{3}$ moieties facing each other are not in the same plane and are not parallel, but form a dihedral angle of $\sim 3.6^{\circ}$, in contrast to 2 . The $\mathrm{C}(\mathrm{CN})_{3}$ moieties are connected to surrounding ET molecules within the Layer-2 through S $\cdots \mathrm{C}(3.33-3.49 \AA)$ and S $\cdots \mathrm{N}$ (3.18-3.19 $\AA$ ) interactions, whereas the bromides are connected to ET molecules within the adjacent Layer-1 through $\mathrm{C}-\mathrm{H} \cdots \mathrm{Br}(2.52-3.04 \AA$ ) hydrogen bonds. Bond distance analysis $^{32}$ has revealed that the ET molecules $(\mathbf{E}$ and $\mathbf{F})$ are in a fully charged state $(+1.18(10)$ for $\mathbf{E}$ and $+1.16(10)$ for $\mathbf{F})$; thus, the face-to-face dimer composed of $\mathbf{E}$ and $\mathbf{F}$ with a ring-over-bond-type overlap as A-B pair in $\mathbf{2}$ (Fig. 3c) appears to be nonmagnetic, with an intra-dimer overlap integral calculated to be $-31.1 \times 10^{-3}$. Because the total charge of Layer-2 in the unit lattice is -3.32(20), the negatively charged Layer-2 is alternately arranged with the positively charged Layer-1 along the $c$ axis.

2.4.3 $(\mathbf{E T})_{3}\left[\mathrm{ZnCl}_{3}\left(\mathrm{H}_{2} \mathrm{O}\right)\right]_{2}\left(\mathrm{H}_{2} \mathrm{O}\right)_{2}(\mathbf{8})$ : Salt 8 was obtained by electrooxidation of ET in the presence of $\mathrm{ZnCl}_{2}, \mathrm{KCl}$, and 18-crown-6 (18C6). Water molecules possibly come from $\mathrm{ZnCl}_{2}$ 
which has high hygroscopicity. A crystallographic study has revealed that this salt belongs to a monoclinic lattice $P 21 / n$ at $298 \mathrm{~K}$ and undergoes a structural phase transition to a lower symmetry state $\left(P 2_{1}\right.$ at $\left.100 \mathrm{~K}\right)$. At $298 \mathrm{~K}$, the asymmetric unit contains one (A) and a half (B) of the ET molecules, one zinc(II) aquachloride $\mathrm{ZnCl}_{3}\left(\mathrm{H}_{2} \mathrm{O}\right)^{-}$ion with pseudotetrahedral geometry, and one $\mathrm{H}_{2} \mathrm{O}$ molecule. On the basis of the bond distance analysis, ${ }^{32}$ charges of ET molecules have been estimated to be $+0.57(8)$ for $\mathbf{A}$ and $+0.75(11)$ for $\mathbf{B}$; charge disproportionation is less significant as compared with that in 7 , and the charge of $+1.89(19)$ per ET triad is consistent with the value expected from this composition (+2). ET molecules are arranged in a $\beta$ " ${ }_{311}$-type packing motif as in the case of many $3: 2$ salts, ${ }^{40,63}$ in which the stacking column extends along the [1 0 -1] direction with an AAB repeating unit (Fig. 10a). In the column, the $\mathbf{A}-\mathbf{B}$ pair consists of a ring-over-atom overlap motif with lateral slipping (Fig. 10b), whereas the $\mathbf{A}-\mathbf{A}$ pair consists of a ring-over-atom overlap motif with oblique slipping (Fig. 10c). Within the $a c$ plane, the columns constitute the layered structure, which is separated by an anionic layer composed of $\mathrm{ZnCl}_{3}\left(\mathrm{H}_{2} \mathrm{O}\right)^{-}$and $\mathrm{H}_{2} \mathrm{O}$.

Figure 10

The $\mathrm{ZnCl}_{3}\left(\mathrm{H}_{2} \mathrm{O}\right)^{-}$species (Fig. 10d) has been reported for salts formed with various cations, such as $\mathrm{K}^{+}{ }^{64} \mathrm{Zn}\left(\mathrm{H}_{2} \mathrm{O}\right)_{6}{ }^{2+}{ }^{65}$ 2-(2-thioxo-1,3-thiazolidin-3-yl)-4,5-dihydro-1,3-thiazolium, ${ }^{66}$ 2-carboxy-6-methylpyridinium, ${ }^{67}$ and benzyltriethylammonium. ${ }^{68}$ The $\mathrm{Zn}-\mathrm{Cl}$ bond lengths at an average of $2.24 \AA$ fall well within the range of distances observed for $\mathrm{ZnCl}_{3}\left(\mathrm{H}_{2} \mathrm{O}\right)$-containing salts (2.21-2.28 $\AA$ ), and the zinc-aqua bond length (2.001 $\AA$ ) is also comparable to those observed for the aforementioned salts (1.98-2.04 $\AA$ ). One of the hydrogen atoms of the aqua ligand is linked to one chloride of neighboring $\mathrm{ZnCl}_{3}\left(\mathrm{H}_{2} \mathrm{O}\right)^{-}$ion through an $\mathrm{OH} \cdots \mathrm{Cl}(2.41 \AA \AA)$ hydrogen bond, whereas the other links to one oxygen atom of 
the solvent water molecule through an $\mathrm{OH} \cdots \mathrm{O}(1.76 \AA$ vs. sum of the van der Waals radii: $2.72 \AA^{39}$ ) hydrogen bond. These intermolecular interactions result in the formation of an infinite 2D network linked by hydrogen bonds.

The band structure, DOS, and Fermi surface of the HOMO band of ET molecules at $298 \mathrm{~K}$ were calculated by assuming uniform charge distribution in the ET layer (i.e. $+0.67 e$ on each ET). As can be seen in Fig. 10e, the highest branch is apparently more dispersive along the $a$ axis than along the $c$ axis, possibly because of the significant transfer integrals along this direction ( $t_{\mathrm{q} 2}$ and $\left.t_{\mathrm{q} 4}\right)$. The Fermi surface consists of an electron pocket centered at the $Z$ point; hence, salt $\mathbf{8}$ is regarded as a 2D electronic system.

Figure 8a includes the temperature dependence of resistivity $(\rho)$ of $\mathbf{8}$, which has a high $\sigma_{\mathrm{RT}}$ value of $55 \mathrm{~S} \mathrm{~cm}^{-1}$ and maintains metallic behavior down to $210 \mathrm{~K}$ where a sharp metal-insulator transition occurs. Its isostructural salts, $\beta{ }^{\prime \prime}{ }_{311}-(\mathrm{ET})_{3}\left(\mathrm{HSO}_{4}\right)_{2}{ }^{69,70}$ and $\left.\beta{ }^{\prime \prime}{ }_{311-(\mathrm{ET})}\right)_{3}\left(\mathrm{ClO}_{4}\right)_{2}{ }^{71}$ undergo a metal-insulator transition at $T_{\mathrm{MI}}=126$ and $170 \mathrm{~K}$, respectively, and the charge-ordered state emerges below these temperatures. ${ }^{72}$ The transition of the $\mathrm{ClO}_{4}$ salt is steadily suppressed by applying pressure, ${ }^{73}$ mainly related to the stabilization of the metallic state. The observed pressure dependence appears to be consistent

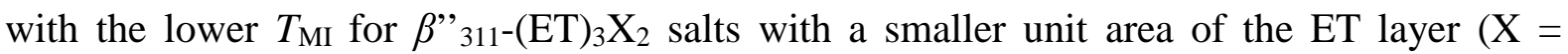
$\mathrm{HSO}_{4}{ }^{-69,70} \mathrm{ClO}_{4}^{-},{ }^{-71,72} \mathrm{BF}_{4}^{-},{ }^{-70,74} \mathrm{BrO}_{4}^{-{ }^{-75}}$ and $\mathrm{Br}^{-76,77}$ ). The fact that salt 8 follows this relation is an explicit demonstration of the emergence of charge ordering at low temperatures. The structural refinement at $100 \mathrm{~K}$, which is far below $T_{\mathrm{MI}}$, is apparently indicative of the lowered crystal symmetry to $P 2_{1}$. Bond length analysis ${ }^{32}$ revealed that the charges of three crystallographically independent ET molecules are +0.51(19), +0.80(19), and +1.01(15), respectively, which may be indicative of the development of charge disproportionation, despite having large standard deviations, probably due to incomplete phase transition. 
2.4.4 (ET) (ZnBr4 $\left._{2}\right)_{2}(\mathrm{TCE})_{2}(\mathbf{E t O H})$ (9): Salt 9 has been frequently obtained by the electrooxidation of ET in the presence of $\mathrm{ZnBr}_{2}$ in a TCE/EtOH mixed solution (Table 1). It crystallizes in a monoclinic lattice $P 2{ }_{1} / c$ at both 100 and $298 \mathrm{~K}$. Three and half ET molecules, one $\mathrm{ZnBr}_{4}{ }^{2-}$ ion, one TCE, and half EtOH are crystallographically independent. As illustrated in Fig. 11a, ET molecules are arranged in a $\theta$-like packing motif ${ }^{42}$ within the $b c$ plane at $x \sim 0$, and each column running along the $c$ axis includes seven ET molecules in a unit cell; five of them (A, B, and $\mathbf{C}$ ) are almost uniformly stacked, while the other two (D), which are related by an inversion center, are dislocated in a direction mutually opposite to each other along the $a$ axis (Fig. 11b). The charges of the ET molecules were estimated to be $+0.37(7),+0.76(8)$, $+0.35(10)$, and $+0.58(7)$ at $100 \mathrm{~K}$ and $+0.65(7),+0.96(7),+0.34(9)$, and $+0.75(7)$ at $298 \mathrm{~K}$ for A-D, respectively, which may be indicative of the emergence of charge disproportionation even at RT.

$* * * * * * * * * *$ Figure 11

The other species, i.e. $\mathrm{ZnBr}_{4}{ }^{2-}$, TCE, and EtOH, are located within the $b c$ plane at $x \sim 0.5$. In the layer, each orientationally disordered EtOH molecule on an inversion center is connected with two $\mathrm{ZnBr}_{4}{ }^{2-}$ through $\mathrm{OH} \cdots \mathrm{Br}$ (2.66 $\AA$ vs. sum of the van der Waals radii: 3.05 $\left.\AA^{39}\right)$ hydrogen bonds and with two TCE through $\mathrm{CH} \cdots \mathrm{Cl}(2.80 \AA)$ hydrogen bonds (Fig. 11c). In addition, short $\mathrm{OH} \cdots \mathrm{Br}(2.91 \AA)$ hydrogen bonds are formed between $\mathrm{ZnBr}_{4}{ }^{2-}$ and TCE, resulting in the formation of an infinite 2D network linked by hydrogen bonds. Notably, there is an anionic hole surrounded by two $\mathrm{ZnBr}_{4}{ }^{2-}$, two TCE, and two EtOH centered at $(1 / 2,0$, 1/2), as can be seen in Fig. 11d. The holes accommodate the disclosed ET molecules (D) in the adjacent layers for stabilizing the peculiar ET arrangement.

Salt 9 exhibits a high $\sigma_{\mathrm{RT}}$ value of $26 \mathrm{~S} \mathrm{~cm}^{-1}$ and the $\rho$ value slightly decreases with 
decreasing temperature at around RT as shown in Fig. 8a; namely, irrespective of the conduction pathway, salt $\mathbf{9}$ behaves metallic at around RT despite possible charge disproportionation. The $\rho$ value passes through a broad minimum at around $270 \mathrm{~K}$ and then increases with decreasing temperature. Transport properties are consistent with the band structures calculated by assuming uniform charge distribution in the ET layer (i.e. +0.57 e on each ET); namely, this salt consists of 1D electron-like and 2D hole-like Fermi surfaces at $298 \mathrm{~K}$ (Fig. 11e), whereas the surface at $100 \mathrm{~K}$ consists only of a tiny hole pocket centered at the $\Gamma$ point (Fig. 11f). Notably, the Fermi level falls near the narrow energy gap region (37 $\mathrm{meV}$ ) at $100 \mathrm{~K}$. Although the salt exhibits some degree of charge disproportionation even at $\mathrm{RT}$, it is likely that the resistivity minimum observed at around $270 \mathrm{~K}$ is attributed to the metal-to-band-insulator transition.

\subsection{Group D}

Salts 10-12 are isostructural at $298 \mathrm{~K}$ (space group $C 2 / m$ ) but behave differently at low temperatures; salt $\mathbf{1 0}$ exhibits a moderate growth of the $c^{* / 2}$ superstructure along the side-by-side direction but undergoes no distinct structural phase transition down to $100 \mathrm{~K}$, whereas salts 11 and 12 undergo a structural phase transition to a lower symmetry state $(C 2 / c$ with a doubled $c$ lattice for $\mathbf{1 1}$ and $P 2_{1} / n$ with a practically unchanged unit cell for $\mathbf{1 2}$ ). Thus, structural comparison is made by considering the crystallographic data at $298 \mathrm{~K}$.

2.5.1 $\theta_{42+40-(E T)}{ }_{4} \mathrm{Zn}(\mathrm{NCS})_{2} \mathrm{X}_{2}(\mathrm{TCE})[\mathrm{X}=\mathrm{Cl}(10)$ and $\mathrm{Br}(11)]$ : Both salts were typically obtained as a sole single-crystalline compound. At $298 \mathrm{~K}$, these salts with isomorphous structures consist of two crystallographically independent ET molecules (A and B), half $\mathrm{Zn}(\mathrm{NCS}){ }_{2} \mathrm{X}_{2}{ }^{2-}$ ion (Fig. 1a), and half TCE molecule; namely, $\mathrm{Zn}(\mathrm{NCS}){ }_{2} \mathrm{X}_{2}{ }^{2-}$ ion and TCE are located on the mirror plane at $y=0$ and 0.5 . In the following section, a discussion focusing on the structural feature of $\mathbf{1 0}$ is present. 
In the crystal, each of the crystallographically independent ET molecules forms a separate column extending along the $a$ axis: Columns 1 for $\mathbf{A}$ and 2 for $\mathbf{B}$ in Fig. 12a. In the 2D layer, ET molecules are arranged in a $\theta_{42+40}$-like packing motif (see below) ${ }^{42}$ in the ac plane at $y \sim$ 0.25 and 0.75 , which are separated by an anionic layer composed of $\mathrm{Zn}(\mathrm{NCS})_{2} \mathrm{Cl}_{2}{ }^{2-}$ and TCE (Fig. $12 \mathrm{~b}$ ). The composition results in a nominal charge of +0.5 on each ET, which appears to be supported by the estimation of the charge of the ET molecules on the basis of bond distance analysis (+0.65(7) for $\mathbf{A}$ and $+0.65(8)$ for $\mathbf{B}$ at $298 \mathrm{~K}$ and $+0.58(7)$ for $\mathbf{A}$ and +0.60 (8) for $\mathbf{B}$ at $100 \mathrm{~K}) .{ }^{32}$ Notably, ET molecules in $\mathbf{1 1}$ also have an equivalent charge at 298 K (+0.59(6) for A and +0.58(7) for B) but exhibit a possible sign of charge disproportionation in Column 1 at $100 \mathrm{~K}(+0.49(8)$ and $+0.63(9)$; $c f .+0.40(8)$ and $+0.44(9)$ in Column 2).

$* * * * * * * * * *$ Figure $12 * * * * * * * * * *$

For a deeper understanding of the molecular packing in the ET layer, the molecular arrangement in the anionic layer at $y \sim 0$ and 0.5 is considered. As can be seen in Fig. 12b, $\mathrm{Zn}(\mathrm{NCS}){ }_{2} \mathrm{Cl}_{2}{ }^{2-}$ ions are dimerized in a face-to-face manner on an inversion center, and each of $\mathrm{Zn}(\mathrm{NCS})_{2} \mathrm{Cl}_{2}{ }^{2-}$ ion is connected to a neighboring disordered TCE molecule through C$\mathrm{H} \cdots \mathrm{Cl}$ hydrogen bonds with an $\mathrm{H} \cdots \mathrm{Cl}$ distance of 2.69-2.83 $\AA$. The anionic layer involves a large cavity (41.8 $\AA^{2}$ for $\mathbf{1 0}$ and $41.5 \AA^{2}$ for $\mathbf{1 1} ;{ }^{78}$ red ellipse in Fig. $12 b$ ) at the center of the ac plane. Figures 12c and 12d show the structural relationship between the ET and anionic layers for Columns 1 and 2, respectively. The ET molecules in Column 1 are arranged in a $\theta_{42}$-type zig-zag manner, which is in contrast to the rather uniform $\theta_{40}$-type array in Column 2. This observation is attributed to the fact that half of ET molecules shift along the molecular long axis to fall into the cavity in the anionic layer. It is important to note that the cavity areas 
are significantly greater than those for quantum spin liquid candidates, $\kappa-(\mathrm{ET})_{2} \mathrm{M}_{2}(\mathrm{CN})_{3}(19.5$ $\AA^{2}$ for $\mathrm{M}=\mathrm{Cu}(\mathrm{I})$ and $15.8 \AA^{2}$ for $\left.\mathrm{M}=\mathrm{Ag}(\mathrm{I})\right){ }^{22}$ in which ET molecules are arranged with respect to the anionic cavities but have no significant shift along the molecular long axis due to the insufficient cavity size. Our recent studies have suggested that such a molecular shift affects the degree of spin frustration in $\kappa$-(ET) $)_{2} \mathrm{X}$ salts $\left(\mathrm{X}=\mathrm{B}(\mathrm{CN})_{4}{ }^{-79}\right.$ and $\left.\mathrm{CF}_{3} \mathrm{SO}_{3}{ }^{-80,81}\right)$. The 'multiple' $\theta$-type ET layer, including different stacking manners in $\mathbf{1 0}$ and 11, can be

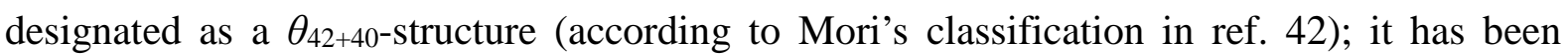
reported for ET salts formed with $\mathrm{M}(\mathrm{CN})_{4}{ }^{2-}(\mathrm{M}=\mathrm{Ni}(\mathrm{II})$ and $\mathrm{Pt}(\mathrm{II})),{ }^{82} \mathrm{SiW}_{12} \mathrm{O}_{40}{ }^{4-}, 83,84$ $\mathrm{PMnW}_{11} \mathrm{O}_{39}{ }^{6-},{ }^{85} \mathrm{PMo}_{12} \mathrm{O}_{40}{ }^{4-},{ }^{84} \mathrm{SMo}_{12} \mathrm{O}_{40}{ }^{3-},{ }^{86}$ and $\mathrm{CoW}_{12} \mathrm{O}_{40}{ }^{6-} .87$

The band structure, DOS, and the Fermi surface of the HOMO band of ET in $\mathbf{1 0}$ and $\mathbf{1 1}$ at $298 \mathrm{~K}$ were calculated by assuming uniform charge distribution in the ET layer (i.e. $+0.50 \mathrm{e}$ on each ET). As can be seen in Fig. 12e, the branches are substantially more dispersive along the side-by-side direction ( $c$ axis) than along the stacking direction ( $a$ axis), possibly because of the significant transfer integrals along the inter-stack direction $\left(t_{c 1}-t_{c 4}\right)$ relative to those within the column $\left(t_{\mathrm{a} 1}-t_{\mathrm{a} 4}\right)$. The alternation of transfer integrals within the columns is not large enough to make an energy gap associated with the dimerization in both Columns 1 and 2. The Fermi surface is composed of a hole pocket centered at the $\Gamma$ point and a quasi-1D electron surface along the $k_{\mathrm{c}}$ direction. The width of the band composed of eight branches was estimated to be 0.876 and $0.864 \mathrm{eV}$ for $\mathbf{1 0}$ and 11, respectively (Table 3). The slightly larger bandwidth in $\mathbf{1 0}$ may be associated with the smaller unit area of the ET layer $(a \sin \beta=$ 190.3 $\AA^{2}$ for $\mathbf{1 0}$ and $191.2 \AA^{2}$ for 11), attributed to the replacement of $\mathrm{Zn}(\mathrm{NCS})_{2} \mathrm{Br}_{2}{ }^{2-}$ with a smaller isomorphic anion, $\mathrm{Zn}(\mathrm{NCS})_{2} \mathrm{Cl}_{2}{ }^{2-}$.

********** Table $3 * * * * * * * * * *$ 
As can be seen in Fig. 13a, both salts have a rather high $\sigma_{\mathrm{RT}}$ value $\left(2.7 \mathrm{~S} \mathrm{~cm}^{-1}\right.$ for $\mathbf{1 0}$ and $1.5 \mathrm{~S} \mathrm{~cm}^{-1}$ for 11) but exhibit semiconducting behavior at around RT ( $E_{\mathrm{a}}=0.19 \mathrm{eV}$ for $\mathbf{1 0}$ at $T>250 \mathrm{~K}$ and $0.15 \mathrm{eV}$ for $\mathbf{1 1}$ at $T>240 \mathrm{~K}$ ). However, the salts behave differently upon cooling; namely, salt $\mathbf{1 1}$ exhibits a marked anomaly at around $200 \mathrm{~K}$, whereas salt $\mathbf{1 0}$ exhibits only a gradual change in the resistivity slope at around $210 \mathrm{~K}$. The critical temperature $\left(T_{0}\right)$, defined as the temperature at which the slope of the curve in Fig. 13a becomes the maximum, was estimated to be $210 \mathrm{~K}$ for $\mathbf{1 0}$ and $200 \mathrm{~K}$ for $\mathbf{1 1}$. The values are comparable to those estimated from the temperature dependence of the intensity $(I)$ at the superlattice Bragg position defined as $I \sim\left(T_{0}-T\right)^{1 / 2}$, which reflects a second-order transition (224 K for $\mathbf{1 0}$ and 189 K for 11; Fig. S2 in Supporting Information).

$* * * * * * * * * *$ Figure $13 * * * * * * * * * *$

Figure 13b shows the Raman spectra of $\mathbf{1 0}$ in the range of $1300-1600 \mathrm{~cm}^{-1}$ at 67 and 250 K, where salt $\mathbf{1 1}$ exhibits a very similar spectrum. ${ }^{88}$ At $250 \mathrm{~K}$, two distinct bands were observed at around 1470 and $1540 \mathrm{~cm}^{-1}$, each of which are split into two components centered at 1452 and $1491 \mathrm{~cm}^{-1}$ for the former and 1541 and $1553 \mathrm{~cm}^{-1}$ for the latter at $67 \mathrm{~K}$. This spectral feature is reminiscent of that of $\theta-(\mathrm{ET})_{2} \mathrm{Cu}_{2}(\mathrm{CN})\left[\mathrm{N}(\mathrm{CN})_{2}\right]_{2}$, which exhibits a pronounced change in the resistivity associated with charge disproportionation at $220 \mathrm{~K}^{89,90}$ Of particular note is that the charge-sensitive $v_{2}$ mode $^{91}$ of $\theta-(\mathrm{ET})_{2} \mathrm{Cu}_{2}(\mathrm{CN})\left[\mathrm{N}(\mathrm{CN})_{2}\right]_{2}$ splits even at RT and continuously changes down to $220 \mathrm{~K} \cdot{ }^{90}$ According to ref. 90, dynamic charge disproportionation occurring even at RT is responsible for the spectral feature. On the other hand, salt 10 exhibits abrupt band splitting at $\sim 1540 \mathrm{~cm}^{-1}$ into 1541 and $1553 \mathrm{~cm}^{-1}$ at around $T_{0}$, supporting the emergence of the charge-disproportionated state below the temperature. Notably, the assignment of the band at $\sim 1470 \mathrm{~cm}^{-1}$, namely either the inclusion of the $v_{2}$ and 
$v_{3}$ modes or the split $v_{3}$ mode, remains a matter of debate. For discriminating between these two possibilities, further spectroscopic studies using ${ }^{13} \mathrm{C}$-enriched ET molecules, in which central double-bonded carbon sites were selectively enriched with the ${ }^{13} \mathrm{C}$ isotope, are in progress. $^{88}$

Figure 14 shows the temperature dependence of $\chi$ of polycrystalline $\mathbf{1 0}$ and $\mathbf{1 1}$ between 1.9 and $300 \mathrm{~K}$, where the salts have two $S=1 / 2$ spins per formula unit. The $\chi$ value at $300 \mathrm{~K}$ is estimated to be $1.92 \times 10^{-3}$ emu mol ${ }^{-1}$ (i.e. $9.6 \times 10^{-4} \mathrm{emu} \mathrm{spin}^{-1}$ ) for $\mathbf{1 0}$ and $1.75 \times 10^{-3} \mathrm{emu}$ $\mathrm{mol}^{-1}$ (i.e. $8.8 \times 10^{-4} \mathrm{emu} \mathrm{spin}^{-1}$ ) for $\mathbf{1 1}$, which exceed that for typical organic metals $(3-5 \times$ $10^{-4}$ emu $\left.\operatorname{spin}^{-1}\right) .{ }^{6}$ The $\chi$ value, in addition to the semiconducting transport behavior, is a characteristic typical of dimer-type Mott insulators. Upon cooling, the $\chi$ value gradually increases down to $c a$. $20 \mathrm{~K}$ followed by a rapid upturn caused by Curie contribution. No anomaly was observed in the measured temperature range, which includes resistivity anomaly. A similar situation has been observed for several charge-ordered system such as $\theta-(\mathrm{ET})_{2} \mathrm{Cu}_{2}(\mathrm{CN})\left[\mathrm{N}(\mathrm{CN})_{2}\right]_{2},{ }^{89,90} \quad \theta-(\mathrm{ET})_{2} \mathrm{RbZn}(\mathrm{SCN})_{4},{ }^{30,31} \quad \theta_{42+40}-(\mathrm{ET})_{4} \mathrm{Pt}(\mathrm{CN})_{4},{ }^{82} \quad$ and $\theta_{42+40}-(\mathrm{ET})_{8} \mathrm{CoW}_{12} \mathrm{O}_{40}\left(\mathrm{H}_{2} \mathrm{O}\right)_{5.5 .}{ }^{87}$ At present, the dimerization pattern is unclear because of comparable intermolecular transfer integrals for the stacking and side-by-side directions. However, provided that charge disproportionation is concluded within an $(\mathrm{ET})_{2}{ }^{\bullet+}$ dimer, charge disproportionation would result in the loss of a significant charge degree of freedom, but would be not accompanied by loss in the spin degree of freedom. The temperature dependence is well described by the sum of the Heisenberg AF linear chain $\left(\chi_{\mathrm{BF}}\right)^{58,59}$ and Curie $\left(\chi_{C}\right)$ models with a fraction $f$ as in the case of 5 (Eq. 1). The best fit parameters were $J=$ 54.7 $\mathrm{K}$ and $f=0.880$ for $\mathbf{1 0}$ and $J=85.4 \mathrm{~K}$ and $f=0.835$ for 11. A significant fraction of the Curie component is believed to rationalize charge disproportionation occurring at low temperatures, because it resembles the case of $\theta$-(ET) $)_{2} \mathrm{CsZn}(\mathrm{SCN})_{4}{ }^{92}$ and rapidly cooled $\theta$-(ET) ${ }_{2} \mathrm{RbZn}(\mathrm{SCN})_{4}{ }^{93}$ in a charge-glass state. ${ }^{94-96}$ In these salts, most of the electrons appear 
to be paired, affording a spin-singlet state, albeit a small fraction of unpaired electrons is maintained down to low temperatures so as to serve as localized paramagnetic spins.

$* * * * * * * * * *$ Figure $14 * * * * * * * * * *$

2.5.2 $\theta_{42+40}-(\mathbf{E T})_{4} \mathrm{Zn}\left[\mathbf{N}(\mathbf{C N})_{2}\right] \mathrm{Cl}_{3}$ (TCE) (12): At $298 \mathrm{~K}$, salt 12 is monoclinic with space group $C 2 / m$ as salts $\mathbf{1 0}$ and $\mathbf{1 1}$ at the same temperature, and an asymmetric unit contains two ET molecules (A and B), half $\mathrm{Zn}\left[\mathrm{N}(\mathrm{CN})_{2}\right] \mathrm{Cl}_{3}{ }^{2-}$ ion with a unidentate-coordinated $\mathrm{N}(\mathrm{CN})_{2}$ moiety (Fig. 1b), and half TCE molecule; namely, $\mathrm{Zn}\left[\mathrm{N}(\mathrm{CN})_{2}\right] \mathrm{Cl}_{3}{ }^{2-}$ and TCE are located on the mirror plane at $y=0$ and 0.5 .

Figures 15a and 15b show the molecular arrangement in the ET and anionic layers within the ac plane at $y \sim 0.25$ and 0 , respectively. In the former layer, each crystallographically independent ET molecule, which has a charge of $+0.78(5)$ for $\mathbf{A}$ and $+0.61(5)$ for $\mathbf{B}$, constructs the stacking column extending along the $a$ axis (Column 1 for $\mathbf{A}$ and 2 for $\mathbf{B}$ ). Similar to 10 and 11, ET molecules in Columns 1 and 2 are arranged in a zig-zag (Fig. 15c) and an almost uniform (Fig. 15d) manners, respectively, for constructing $\theta_{42+40 \text {-type }}$ molecular arrangement. Notably, the zig-zag arrangement appeared in Column 1 is attributed to the steric hindrance of chlorides in $\mathrm{Zn}\left[\mathrm{N}(\mathrm{CN})_{2}\right] \mathrm{Cl}_{3}{ }^{2-}$ and TCE, connected through $\mathrm{C}-$ $\mathrm{H} \cdots \mathrm{Cl}$ hydrogen bonds with an $\mathrm{H} \cdots \mathrm{Cl}$ distance of 2.66-2.79 $\AA$, in the anionic layer.

Figure 15

At $100 \mathrm{~K}$, salt 12 has the structure with a lower symmetry space group $\left(P 2_{1} / n\right)$. Although high refinement factors $\left(R_{1}\right.$ (for $\left.\left.I>2 \sigma(I)\right)=0.0755\right)$ and high standard deviations on atomic coordinates are present, the estimated charges on ET molecules on the basis of intramolecular 
bond lengths $(+0.54(13)$ and $+0.40(13)$ in Column 1 and $+0.87(14)$ and $+0.23(13)$ in Column 2) are indicative of the appearance of the charge-disproportionated state at least in Column 2. The estimated charges are somewhat different from those in $\mathbf{1 0}$ and 11, although the Raman spectra of $\mathbf{1 2}$ are very similar to those of $\mathbf{1 0}$ and $\mathbf{1 1},{ }^{88}$ as well as those of $\theta-(\mathrm{ET})_{2} \mathrm{Cu}_{2}(\mathrm{CN})\left[\mathrm{N}(\mathrm{CN})_{2}\right]_{2} \cdot{ }^{90}$ This discrepancy may be associated with the possible dynamical fluctuation of the charges in the ET layers in these salts. The temperature dependence of the intensity at the superlattice Bragg position follows the equation $I \sim\left(T_{0}-\right.$ $T)^{1 / 2}$ for a second-order transition, where the $T_{0}$ value was estimated to be $253 \mathrm{~K}$ (Fig. S2 in Supporting Information).

Figure 15e displays the band structure, DOS, and Fermi surface of the HOMO band of ET in $\mathbf{1 2}$ at $298 \mathrm{~K}$, which is reminiscent of those of isostructural salts $\mathbf{1 0}$ and $\mathbf{1 1}$. The bandwidth of the HOMO band was estimated to be $0.947 \mathrm{eV}$, significantly greater than those of $\mathbf{1 0}$ $(0.876 \mathrm{eV})$ and $\mathbf{1 1}(0.864 \mathrm{eV})$. This result is mainly attributed to the shrinkage of ET layers in $\mathbf{1 2}$ relative to $\mathbf{1 0}$ and $\mathbf{1 1}$; namely, the $a \sin \beta$ value changes from $190.3 \AA^{2}$ for $\mathbf{1 0}$ and $191.2 \AA^{2}$ for $\mathbf{1 1}$ to $189.3 \AA^{2}$ for $\mathbf{1 2}$. Such lattice shrinkage results in a decreased dihedral angle between the ET planes in adjacent columns (124.9 ${ }^{\circ}$ for $\mathbf{1 2}$ vs. $127.6^{\circ}$ for $\mathbf{1 0}$ and $128.1^{\circ}$ for $\left.\mathbf{1 1}\right)$.

The temperature dependence of $\rho$ of $\mathbf{1 2}$ is shown in Figure 13a. As in the case in $\mathbf{1 0}$ and $\mathbf{1 1}$, salt 12 has a rather high $\sigma_{\mathrm{RT}}$ value $\left(4.8 \mathrm{~S} \mathrm{~cm}^{-1}\right)$ and exhibits semiconducting behavior with $E_{\mathrm{a}}$ $=0.11 \mathrm{eV}$ at around RT. On cooling, the $\rho$ value exhibits a slope maximum at around $230 \mathrm{~K}$, comparable to that estimated from the intensity of superlattice reflection $\left(T_{0}=253 \mathrm{~K}\right)$. As can be seen in the inset of Fig. 13a, the $T_{0}$ values steadily decrease with increasing acsin $\beta$, possibly attributed to the stabilization of the low-temperature charge-disproportionated phase by the shrinkage of ET layers. The magnetic susceptibility of $\mathbf{1 2}$ indicates a similar temperature dependence to those of $\mathbf{1 0}$ and 11, with $J=47.2 \mathrm{~K}$ and $f=0.842$ (Fig. 14c) and no noticeable anomaly at $T_{0}$. Considering the larger $W$ and lower $E_{\text {a }}$ values, the smaller $J$ 
value appears to arise from the more itinerant nature of the carriers in the ET layers of $\mathbf{1 2 .}$

\section{Conclusion}

In this study, a series of ET salts composed of various zinc(II) complex anions, with properties ranging from metallic behavior to band and charge-ordered insulators, were prepared. The key issue is the chemical instability of $\mathrm{ZnX}_{2}$ species, which allows the additional reactions to proceed during electrocrystallization. The resultant complex anions possess a tetrahedrally coordinated structure, unlike planar trigonal coordination for copper(I) and silver(I) complex anions; hence, sterically bulky structures inevitably affect the molecular arrangement in adjacent ET layers. For examples, the large cavities in the anionic layer result in the extrusion of neighboring ET molecules, affording a specific ET packing motif, whereas the penetration of a part of the sterically bulky anions in the ET layer results in the isolation of ET dimers or tetramers. As the present results have significant implications for the diverse production of zinc(II) complex anions by the coordination of various (pseudo)halide ligands, such zinc(II) complex anions may serve as a template for a new strategy for the molecular arrangement of cation radical species, which are responsible for electronic functionalities. Even though the ligand species are the same, one can significantly promote the further exploration of unprecedented cation radical salts by utilizing ligands with multi-coordination sites. For example, the unidentate coordination of the $\mathrm{N}(\mathrm{CN})_{2}$ moiety affords a discrete dianion $\mathrm{Zn}\left[\mathrm{N}(\mathrm{CN})_{2}\right] \mathrm{Cl}_{3}{ }^{2-}$ (in 12), which has stoichiometry, geometry, and charge different from those of a polyanion $\left\{\mathrm{Zn}\left[\mathrm{N}(\mathrm{CN})_{2}\right] \mathrm{Cl}_{2}{ }^{-}\right\}_{\infty}$ (in 6), in which $\mathrm{N}(\mathrm{CN})_{2}$ moieties serve as a $\mu_{1,5}$-bidentate bridging ligand, affording a $1 \mathrm{D}$ polymeric structure. In addition, the sterically bulky complex anions appear to have an ability to include solvent molecules in the crystals; therefore, the change in solvent is also effective for controlling the arrangement in the radical cations. 


\section{Experiments}

General. 1,1,2-trichloroethane was used as received, whereas $\mathrm{MeOH}$, EtOH, and MeCN were distilled prior to use. Zinc salts $\left(\mathrm{ZnCl}_{2}, \mathrm{ZnBr}_{2}\right.$, and $\left.\mathrm{ZnSCN}\right), \mathrm{KCl}, \mathrm{KBr}, \mathrm{KB}(\mathrm{CN})_{4}$, and $\left(\mathrm{Ph}_{4} \mathrm{P}\right) \mathrm{Cl}$ were used as received. $\mathrm{KSCN}$ and $\mathrm{KC}(\mathrm{CN})_{3}$ were recrystallized from $\mathrm{EtOH}$, whereas 18C6 was recrystallized from $\mathrm{MeCN}$. $\left(\mathrm{Bu}_{4} \mathrm{~N}\right) \mathrm{Au}(\mathrm{CN})_{2}$ was prepared by the metathesis of $\left(\mathrm{Bu}_{4} \mathrm{~N}\right) \mathrm{I}$ with $\mathrm{KAu}(\mathrm{CN})_{2}$ in water, followed by recrystallization from EtOH. $\mathrm{Ph}_{4} \mathrm{P}$ salts $\left[\left(\mathrm{Ph}_{4} \mathrm{P}\right) \mathrm{SCN},\left(\mathrm{Ph}_{4} \mathrm{P}\right) \mathrm{N}(\mathrm{CN})_{2}\right.$, and $\left.\left(\mathrm{Ph}_{4} \mathrm{P}\right) \mathrm{C}(\mathrm{CN})_{3}\right]$ were prepared by the metathesis of $\left(\mathrm{Ph}_{4} \mathrm{P}\right) \mathrm{Cl}$ with appropriate alkali metal salts in water, followed by recrystallization from EtOH.

Electrocrystallization. Single crystals of ET salts were obtained by the electrochemical oxidation of ET in an H-shaped glass cell, which was assembled in a glove box filled with argon gas $\left(\mathrm{H}_{2} \mathrm{O}, \mathrm{O}_{2}<1 \mathrm{ppm}\right.$; Table 1). Typically, $0.02 \mathrm{mmol}$ of ET and $0.08 \mathrm{mmol}$ of other reagents were added to the anodic and cathodic compartments, respectively, separated by a glass frit. After the cell was dried under vacuum, $18 \mathrm{~mL}$ of appropriate solvent(s) was added to the cell, and the mixture was stirred at RT for 1-2 days. A constant current $(1.0 \mu \mathrm{A})$ was passed between the two platinum electrodes at a constant temperature of 15 or $20{ }^{\circ} \mathrm{C}$. Black crystals were grown on the anodic electrode over approximately two weeks. The obtained crystals were washed with $\mathrm{MeOH}$ and dried in air. In some cases, crystals of a known ET cation radical salt $\delta$-(ET) $)_{2} \mathrm{C}(\mathrm{CN})_{3},{ }^{97}$ which is free of zinc(II), were obtained.

Crystal structure determination. X-ray diffraction experiments were performed on a CCD-type diffractometer (Bruker SMART APEX II) with graphite-monochromated Mo Ka radiation (50 kV, $30 \mathrm{~mA})$ at a controlled temperature (100-298 K). A crystal was mounted on a glass capillary and cooled by a stream of cooled nitrogen gas. Crystal structures were solved using a direct method using the SIR2004 program $^{98}$ and were refined by a full-matrix 
least-squares method on $F^{2}$ using the SHELXL program..$^{99}$ Positional parameters were refined using anisotropic temperature factors except for the hydrogen atoms.

Electrical resistivity. The d.c. conductivity was measured using the standard four-probe technique. Four gold wires $(\phi 10-20 \mu \mathrm{m})$ were attached to a single crystal with carbon paint (Jeol Dotite Paint XC-12). A constant electric current of less than $100 \mu \mathrm{A}$ was applied along the stacking direction.

Magnetic susceptibility. A quantum design MPMS-XL superconducting quantum interference device (SQUID) magnetometer was used for collecting magnetic susceptibility data for polycrystalline samples between 1.9 and $300 \mathrm{~K}$ in an applied magnetic field of $1 \mathrm{~T}$.

Raman spectroscopy. Raman scattering spectra were collected in backscattering configuration using a microscopic Raman spectrometer (Renishaw inVia). The excitation light source was a He-Ne Laser $(1.96 \mathrm{eV}, 632.8 \mathrm{~nm})$. The polarization direction of the incident light is perpendicular to the $a$ axis (stacking direction) on the $a c$ plane for $\mathbf{1 0}-\mathbf{1 2}$. The polarization of the detected light is parallel to that of the incident light. Temperature dependence was measured using a cryostat (Oxford Microstat).

Band structure calculations. Overlap integrals (s) between HOMOs of ET molecules were calculated via the extended Hückel method. Parameters for Slater-type atomic orbitals were taken from ref. 100 for hydrogen and carbon and from ref. 101 for sulfur, where the 3d orbital of a sulfur atom was included in the calculation. Transfer integrals $(t)$ estimated assuming $t=E s(E=-10 \mathrm{eV})$ were utilized for band calculations within the tight-binding approximation. All the calculations were performed using the program developed by Mori et $a^{33}$

Acknowledgements. The authors thank Prof. Takehiko Mori for technical support in band calculations. This work was supported by the Japan Society for the Promotion of Science 
(JSPS) KAKENHI Grant Numbers JP23225005, JP25288041, JP26110512, JP26288035, JP16H00964, and JP16H04139.

Supporting Information Available: Calculated band structure for 6 (Fig. S1), temperature dependence of the intensity at the superlattice Bragg positions for 10-12 (Fig. S2), and X-ray crystallographic data in CIF format. This material is available free of charge via the Internet at http://pubs.acs.org.

\section{Corresponding Author}

Phone: +81-52-838-2552. Fax: +81-52-833-7200. E-mail: yyoshida@meijo-u.ac.jp.

\section{References}

(1) Ishiguro, T.; Yamaji, K.; Saito, G. Organic Superconductors, 2nd ed.; Springer; Berlin, 1998.

(2) Chem. Rev. 2004, 104, Issue 11.

(3) J. Phys. Soc. Jpn. 2006, 75, Issue 5.

(4) Crystals 2012, 2, Issue 3.

(5) Eur. J. Inorg. Chem. 2014, 2014, Issue 24.

(6) Saito, G.; Yoshida, Y. Bull. Chem. Soc. Jpn. 2007, 80, 1-137.

(7) Dressel, M. J. Phys.: Condens. Matter 2011, 23, 293201.

(8) Kanoda, K.; Kato, R. Annu. Rev. Condens. Matter Phys. 2011, 2, 167-188.

(9) Urayama, H.; Yamochi, H.; Saito, G.; Nozawa, K.; Sugano, T.; Kinoshita, M.; Sato, S.; Oshima, K.; Kawamoto, A.; Tanaka, J. Chem. Lett. 1988, 17, 55-58.

(10) Urayama, H.; Yamochi, H.; Saito, G.; Sato, S.; Kawamoto, A.; Tanaka, J.; Mori, T.; Maruyama, Y.; Inokuchi, H. Chem. Lett. 1988, 17, 463-466. 
(11) Kini, A. M.; Geiser, U.; Wang, H. H.; Carlson, K. D.; Williams, J. M.; Kwok, W. K.; Vandervoort, K. G.; Thompson, J. E.; Stupka, D. L.; Jung, D.; Whangbo, M.-H. Inorg. Chem. 1990, 29, 2555-2557.

(12) Williams, J. M.; Kini, A. M.; Wang, H. H.; Carlson, K. D.; Geiser, U.; Montgomery, L. K.; Pyrka, G. J.; Watkins, D. M.; Kommers, J. M.; Boryschuk, S. J.; Crouch, A. V. S.; Kwok, W. K.; Schirber, J. E.; Overmyer, D. L.; Jung, D.; Whangbo, M.-H. Inorg. Chem. 1990, 29, 3272-3274.

(13) Wang, H. H.; Carlson, K. D.; Geiser, U.; Kini, A. M.; Schultz, A. J.; Williams, J. M.; Montgomery, L. K.; Kwok, W. K.; Welp, U.; Vandervoort, K. G.; Boryschuk, S. J.; Strieby Crouch, A. V.; Kommers, J. M.; Watkins, D. M.; Schirber, J. E.; Overmyer, D. L.; Jung, D.; Novoa, J. J.; Whangbo, M.-H. Synth. Met. 1991, 41-43, 1983-1990.

(14) Miyagawa, K.; Kawamoto, A.; Nakazawa, Y.; Kanoda, K. Phys. Rev. Lett. 1995, 75, 1174-1177.

(15) Kushch, N. D.; Tanatar, M. A.; Yagubskii, E. B.; Ishiguro, T. JETP Lett. 2001, 73, 429431.

(16) Kagawa, F.; Miyagawa, K.; Kanoda, K. Nature 2005, 436, 534-537.

(17) Bu, X.; Frost-Jensen, A.; Allendoerfer, R.; Coppens, P. Solid State Commun. 1991, 79, 1053-1057.

(18) Geiser, U.; Wang, H. H.; Carlson, K. D.; Williams, J. M.; Charlier, H. A.; Heindl, J. E.; Yaconi, G. A.; Love, B. J.; Lathrop, M. W.; Schirber, J. E.; Overmyer, D. L.; Ren, J.; Whangbo, M.-H. Inorg. Chem. 1991, 30, 2586-2588.

(19) Shimizu, Y.; Miyagawa, K.; Kanoda, K.; Maesato, M.; Saito, G. Phys. Rev. Lett. 2003, 91, 107001.

(20) Yoshida, Y.; Hayama, H.; Ishikawa, M.; Otsuka, A.; Yamochi, H.; Nakamura, Y.; Kishida, H.; Ito, H.; Maesato, M.; Saito, G. J. Phys. Soc. Jpn. 2015, 84, 123801. 
(21) Shimizu, Y.; Hiramatsu, T.; Maesato, M.; Otsuka, A.; Yamochi, H.; Ono, A.; Itoh, M.; Yoshida, M.; Takigawa, M.; Yoshida, Y.; Saito, G. Phys. Rev. Lett. 2016, 117, 107203.

(22) Hiramatsu, T.; Yoshida, Y.; Saito, G.; Otsuka, A.; Yamochi, H.; Maesato, M.; Shimizu, Y.; Ito, H.; Nakamura, Y.; Kishida, H.; Watanabe, M.; Kumai, R. to be submitted.

(23) Erxleben, A. Coord. Chem. Rev. 2003, 246, 203-228.

(24) Shibaeva, R. P.; Lobkovskaya, R. M.; Korotkov, V. E.; Kushch, N. D.; Yagubskii, É. B.; Makova, M. K. Synth. Met. 1988, 27, A457-A463.

(25) Shibaeva, R. P.; Rozenberg, L. P.; Kushch, N. D.; Ignatiev, A. A.; Yagubskii. E. B.; Laukhin, V. N.; Makova, M. K.; Merzhanov, V. A. Synth. Met. 1991, 42, 2215.

(26) Zhilyaeva, E. I.; Dzyuba, K. A.; Flakina, A. M.; Shilov, G. V.; Kulikov, A. V.; Lyubovskii, R. B.; Lyubovskaya, R. N. Russ. Chem. Bull. 2013, 62, 1636-1642.

(27) Zhilyaeva, E. I.; Dzyuba, K. A.; Torunova, S. A.; Flakina, A. M.; Shilov, G. V.; Kulikov, A. V.; Lyubovskaya, R. N. Synth. Met. 2015, 209, 329-336.

(28) Mori, H.; Tanaka, S.; Mori, T.; Maruyama, Y. Bull. Chem. Soc. Jpn. 1995, 68, 11361144.

(29) Komatsu, T.; Kojima, N.; Saito, G. Solid State Commun. 1997, 103, 519-523.

(30) Mori, H.; Tanaka, S.; Mori, T.; Kobayashi, A.; Kobayashi, H. Bull. Chem. Soc. Jpn. 1998, 71, 797-806.

(31) Mori, H.; Tanaka, S.; Mori, T. Phys. Rev. B 1998, 57, 12023-12029.

(32) Guionneau, P.; Kepert, C. J.; Bravic, G.; Chasseau, D.; Truter, M. R.; Kurmoo, M.; Day, P. Synth. Met. 1997, 86, 1973-1974. Standard deviations of the charges, which were estimated using empirical formula reported in ref. 32, described in the present paper, come only from those of crystallographic data. Notably, the empirical formula was made using a series of data with an error of about $10 \%$. 
(33) Mori, T.; Kobayashi, A.; Sasaki, Y.; Kobayashi, H.; Saito, G.; Inokuchi, H. Bull. Chem. Soc. Jpn. 1984, 57, 627-633.

(34) Martin, J. D.; Canadell, E.; Batail, P. Inorg. Chem. 1992, 31, 3176-3178.

(35) Kepert, C. J.; Kurmoo, M.; Day, P. Inorg. Chem. 1997, 36, 1128-1135.

(36) Turner, S. S.; Day, P.; Gelbrich, T.; Hursthouse, M. B. J. Solid State Chem. 2001, 159, $385-390$.

(37) Turner, S. S.; Le Pévelen, D.; Day, P.; Prout, K. J. Solid State Chem. 2002, 168, 573581.

(38) Brooks, A. C.; Martin, L.; Day, P.; Clegg, W.; Harrington, R. W.; Wallis, J. D. Polyhedron 2015, 102, 75-81.

(39) Bondi, A. J. Phys. Chem. 1964, 68, 441-451.

(40) Mori, T. Bull. Chem. Soc. Jpn. 1998, 71, 2509-2526.

(41) Mori, T. Bull. Chem. Soc. Jpn. 1999, 72, 2011-2027.

(42) Mori, T.; Mori, H.; Tanaka, S. Bull. Chem. Soc. Jpn. 1999, 72, 179-197.

(43) Zang, S.-Q.; Zhao, L.; Mak, T. C. W. Organometallics 2008, 27, 2396-2398.

(44) Taniguchi, H.; Miyashita, M.; Uchiyama, K.; Satoh, K.; Môri, N.; Okamoto, H.; Miyagawa, K.; Kanoda, K.; Hedo, M.; Uwatoko, Y. J. Phys. Soc. Jpn. 2003, 72, 468471.

(45) Kano, M.; Uchiyama, K.; Taniguchi, H.; Hedo, M.; Matsubayashi, K.; Uwatoko, Y. J. Phys.: Conf. Ser. 2009, 150, 052093.

(46) Triki, S.; Ouahab, L.; Grandjean, D. Acta Cryst. C 1991, 47, 645-648.

(47) Saito, G.; Izukashi, H.; Shibata, M.; Yoshida, K.; Kushch, L. A.; Kondo, T.; Yamochi, H.; Drozdova, O. O.; Matsumoto, K.; Kusunoki, M.; Sakaguchi, K.; Kojima, N.; Yagubskii, E. B. J. Mater. Chem. 2000, 10, 893-910.

(48) Chandra, V. R.; Sen, D.; Ivanov, N. B.; Richter, J. Phys. Rev. B 2004, 69, 214406. 
(49) Nomura, K.; Okamoto, K. J. Phys. Soc. Jpn. 1993, 62, 1123-1126.

(50) Maeshima, N.; Okunishi, K. Phys. Rev. B 2000, 62, 934-939.

(51) Takano, K.; Kubo, K.; Sakamoto, H. J. Phys.: Condens. Matter 1996, 8, 6405-6412.

(52) Tonegawa, T.; Okamoto, K.; Hikihara, T.; Takahashi, Y.; Kaburagi, M. J. Phys. Soc. Jpn. (Suppl. A) 2000, 69, 332-338.

(53) Schulenburg, J.; Richter, J. Phys. Rev. B 2002, 66, 134419.

(54) Helis, H. M.; Goodman, W. H.; Wilson, R. B.; Morgan, J. A.; Hodgson, D. J. Inorg. Chem. 1977, 16, 2412-2416.

(55) Kikuchi, H.; Nagasawa, H.; Ajiro, Y.; Asano, T.; Goto, T. Physica B 2000, 284-288, $1631-1632$.

(56) Khan, M. I.; Giri, S.; Ayesh, S.; Doedens, R. J. Inorg. Chem. Commun. 2004, 7, 721724.

(57) Kikuchi, H.; Ishikawa, Y.; Fujii, Y.; Matsuo, A.; Kindo, K. J. Phys.: Conf. Ser. 2014, 568, 042017.

(58) Bonner, J. C.; Fisher, M. E. Phys. Rev. 1964, 135, A640-A658.

(59) Estes, W. E.; Gavel, D. P.; Hatfield, W. E.; Hodgson, D. J. Inorg. Chem. 1978, 17, $1415-1421$.

(60) Seo, H. J. Phys. Soc. Jpn. 2000, 69, 805-820.

(61) Seo, H.; Hotta, C.; Fukuyama, H. Chem. Rev. 2004, 104, 5005-5036.

(62) Line, M. E. J. Phys. Chem. Solids 1970, 31, 101-116.

(63) Mori, T. Chem. Rev. 2004, 104, 4947-4969.

(64) Brehler, B. Süsse, P. Naturwissenschaften 1963, 50, 517.

(65) Doxsee, K. M.; Hagadorn, J. R.; Weakley, T. J. R. Inorg. Chem. 1994, 33, 2600-2606.

(66) Kubiak, M.; Glowiak, T. Acta Cryst. C 1986, 42, 419-421.

(67) Pons, J.; Rius, J.; Ros, J. Inorg. Chim. Acta 2006, 359, 379-382. 
(68) Jin, L. Acta Cryst. E 2011, 67, m1793.

(69) Porter, L. C.; Wang, H. H.; Miller, M. M.; Williams, J. M. Acta Cryst. C 1987, 43, 2201-2203.

(70) Kushch, N. D.; Yagubskii, E. B.; Korotkov, V. E.; Shibaeva, R. P.; Buravov, L. I.; Zvarykina, A. V.; Laukhin, V. N.; Khomenko, A. G. Synth. Met. 1991, 42, 2131-2134.

(71) Kobayashi, H.; Kato, R.; Mori, T.; Kobayashi, A.; Sasaki, Y.; Saito, G.; Enoki, T.; Inokuchi, H. Chem. Lett. 1984, 13, 179-182.

(72) Yamamoto, T.; Uruichi, M.; Yakushi, K.; Kawamoto, A. Phys. Rev. B 2006, 73, 125116.

(73) Imaeda, K.; Enoki, T.; Saito, G.; Inokuchi, H. Bull. Chem. Soc. Jpn. 1988, 61, 33323334.

(74) Parkin, S. S. P.; Engler, E. M.; Lee, V. Y.; Schumaker, R. R. Mol. Cryst. Liq. Cryst. 1985, 119, 375-387.

(75) Beno, M. A.; Blackman, G. S.; Leung, P. C. W.; Carlson, K. D.; Copps, P. T.; Williams, J. M. Mol. Cryst. Liq. Cryst. 1985, 119, 409-412.

(76) Urayama, H.; Saito, G.; Kawamoto, A.; Tanaka, J. Chem. Lett. 1987, 16, 1753-1756.

(77) Urayama, H.; Saito, G.; Sugano, T.; Kinoshita, M.; Kawamoto, A.; Tanaka, J. Synth. Met. 1988, 27, A401-A406.

(78) The cavity area within the anionic layer was defined as the area that is not occupied by the van der Waals spheres of the atoms of $\mathrm{Zn}(\mathrm{NCS})_{2} \mathrm{X}_{2}^{-}$and TCE.

(79) Yoshida, Y.; Ito, H.; Maesato, M.; Shimizu, Y.; Hayama, H.; Hiramatsu, T.; Nakamura, Y.; Kishida, H.; Koretsune, T.; Hotta, C.; Saito, G. Nat. Phys. 2015, 11, 679-683.

(80) Fettouhi, M.; Ouahab, L.; Gómez-García, C.; Ducasse, L.; Delhaès, P. Synth. Met. 1995, 70, 1131-1132.

(81) Ito, H.; Asai, T.; Shimizu, Y.; Hayama, H.; Yoshida, Y.; Saito, G. Phys. Rev. B 2016, 94, 020503(R). 
(82) Fettouhi, M.; Ouahab, L.; Grandjean, D.; Ducasse, L.; Amiell, J.; Canet, R.; Delhaès, P. Chem. Mater. 1995, 7, 461-471.

(83) Davidson, A.; Boubekeur, K.; Pénicaud, A.; Auban, P.; Lenoir, C.; Batail, P.; Hervé, G. J. Chem. Soc., Chem. Commun. 1989, 1373-1374.

(84) Bellitto, C.; Bonamico, M.; Fares, V.; Federici, F.; Righini, G.; Kurmoo, M.; Day, P. Chem. Mater. 1995, 7, 1475-1484.

(85) Galán-Mascarós, J. R.; Giménez-Saiz, C.; Triki, S.; Gómez-García, C. J.; Coronado, E.; Ouahab, L. Angew. Chem. Int. Ed. Engl. 1995, 34, 1460-1462.

(86) Coronado, E.; Curreli, S.; Giménez-Saiz, C.; Gómez-García, C. J.; Alberola, A.; Canadell, E. Inorg. Chem. 2009, 48, 11314-11324.

(87) Gómez-García, C. J.; Ouahab, L.; Gimenez-Saiz, C.; Triki, S.; Coronado, E.; Delhaès, P. Angew. Chem. Int. Ed. Engl. 1994, 33, 223-226.

(88) Nakamura, Y.; Kishida, H., et al., to be submitted.

(89) Komatsu, T.; Sato, H.; Nakamura, T.; Matsukawa, N.; Yamochi, H.; Saito, G.; Kusunoki, M.; Sakagushi, K.; Kagoshima, S. Bull Chem. Soc. Jpn. 1995, 68, 2233-2244.

(90) Yamamoto, T.; Yakushi, K.; Shimizu, Y.; Saito, G. J. Phys. Soc. Jpn. 2004, 73, 23262332.

(91) Yakushi, K. Crystals 2012, 2, 1291-1346.

(92) Nakamura, T.; Minagawa, W.; Kinami, R.; Takahashi, T. J. Phys. Soc. Jpn. 2000, 69, 504-509.

(93) Yamaguchi, T.; Kimata, M.; Hazama, K.; Terashima, T.; Uji, S.; Konoike, T.; Yamamoto, H. M. Phys. Rev. B 2010, 81, 235110.

(94) Nad, F.; Monceau, P.; Yamamoto, H. M. Phys. Rev. B 2007, 76, 205101.

(95) Kagawa, F.; Sato, T.; Miyagawa, K.; Kanoda, K.; Tokura, Y.; Kobayashi, K.; Kumai, R.; Murakami, Y. Nat. Phys. 2013, 9, 419-422. 
(96) Oike, H.; Kagawa, F.; Ogawa, N.; Ueda, A.; Mori, H.; Kawasaki, M.; Tokura, Y. Phys. Rev. B 2015, 91, 041101.

(97) Beno, M. A.; Wang, H. H.; Soderholm, L.; Carlson, K. D.; Hall, L. N.; Nuñez, L.; Rummens, H.; Anderson, B.; Schlueter, J. A.; Williams, J. M.; Whangbo, M.-H.; Evain, M. Inorg. Chem. 1989, 28, 150-154.

(98) Burla, M. C.; Caliandro, R.; Camalli, M.; Carrozzini, B.; Cascarano, G. L.; De Caro, L.; Giacovazzo, C.; Polidori, G.; Spagna, R. J. Appl. Crystallogr. 2005, 38, 381-388.

(99) Sheldrick, G. M. SHELXL-2013; University of Göttingen, Germany, 2013.

(100) Summerville, R.; Hoffmann, R. J. Am. Chem. Soc. 1976, 98, 7240-7254.

(101) Chen, M. M. L.; Hoffmann, R. J. Am. Chem. Soc. 1976, 98, 1647-1653. 
Table 1. Composition, average charge of ET molecules, and anionic reactions during the electrocrystallization $\left(\mathrm{ZnX}_{2}+\mathrm{Y}_{\mathrm{A}}^{-}+\mathrm{Y}_{\mathrm{B}}{ }^{-} \rightarrow\right.$ $\left.\mathrm{ZnX}_{2} \mathrm{Y}_{\mathrm{A}} \mathrm{Y}_{\mathrm{B}}^{2-}\right)$

\begin{tabular}{|c|c|c|c|c|c|c|c|c|}
\hline & Composition & $\begin{array}{l}\text { Ave. charge of } \\
\text { ET molecules }\end{array}$ & Anion & $\begin{array}{l}\mathrm{X}^{-} \text {of } \\
\mathrm{ZnX} \mathrm{X}_{2}\end{array}$ & $\mathrm{YA}_{\mathrm{A}^{-}}$ & $\mathrm{Y}_{\mathrm{B}}^{-}$ & Reagents $^{b}$ & Solvents ${ }^{c}$ \\
\hline \multicolumn{9}{|c|}{ Group A } \\
\hline 1 & $2: 1$ & +1 & $\mathrm{Zn}\left[\mathrm{C}(\mathrm{CN})_{3}\right] \mathrm{Cl}_{3}{ }^{2-}$ & $\mathrm{Cl}^{-}$ & $\mathrm{C}(\mathrm{CN})_{3}^{-}$ & $\mathrm{Cl}^{-}$ & $\mathrm{ZnCl}_{2}, \mathrm{KC}(\mathrm{CN})_{3}, \mathrm{KCl}, 18 \mathrm{C} 6$ & $\mathrm{TCE}^{d}$ \\
\hline 2 & $2: 1$ & +1 & $\mathrm{Zn}\left[\mathrm{C}(\mathrm{CN})_{3}\right] \mathrm{Br}_{3}{ }^{2-}$ & $\mathrm{Br}^{-}$ & $\mathrm{C}(\mathrm{CN})_{3}^{-}$ & $\mathrm{Br}^{-}$ & $\mathrm{ZnBr} 2, \mathrm{KC}(\mathrm{CN})_{3}, \mathrm{KBr}, 18 \mathrm{C} 6$ & TCE \\
\hline 3 & $2: 1$ & +1 & $\mathrm{Zn}\left[\mathrm{Au}(\mathrm{CN})_{2}\right] \mathrm{Cl}_{3}^{2-}$ & $\mathrm{Cl}^{-}$ & $\mathrm{Au}(\mathrm{CN})_{2}^{-}$ & $\mathrm{Cl}^{-}$ & $\mathrm{ZnCl}_{2},\left(\mathrm{Bu}_{4} \mathrm{~N}\right) \mathrm{Au}(\mathrm{CN})_{2}$ & TCE/EtOH(17:1) \\
\hline 4 & 2:1:0.5(EtOH) & +1 & $\mathrm{Zn}\left[\mathrm{Au}(\mathrm{CN})_{2}\right] \mathrm{Br}^{2-}$ & $\mathrm{Br}^{-}$ & $\mathrm{Au}(\mathrm{CN})_{2}^{-}$ & $\mathrm{Br}^{-}$ & $\mathrm{ZnBr}_{2},(\mathrm{Bu} 4 \mathrm{~N}) \mathrm{Au}(\mathrm{CN})_{2}$ & TCE/EtOH(17:1) \\
\hline \multicolumn{9}{|c|}{ Group B } \\
\hline 5 & $2: 1$ & +1 & $\mathrm{Zn}\left[\mathrm{C}(\mathrm{CN})_{3}\right]_{2} \mathrm{Br}_{2}{ }^{2-}$ & $\mathrm{Br}^{-}$ & $\mathrm{C}(\mathrm{CN})_{3}^{-}$ & $\mathrm{C}(\mathrm{CN})_{3}^{-}$ & $\mathrm{ZnBr} 2,\left(\mathrm{Ph}_{4} \mathrm{P}\right) \mathrm{C}(\mathrm{CN})_{3}$ & TCE/EtOH(17:1) \\
\hline \multicolumn{9}{|c|}{ Group C } \\
\hline 6 & 2:1:0.5(TCE) & +0.5 & $\left\{\mathrm{Zn}\left[\mathrm{N}(\mathrm{CN})_{2}\right] \mathrm{Cl}_{2}^{-}\right\}_{\infty}$ & $\mathrm{Cl}^{-}$ & $1 / 2 \mathrm{~N}(\mathrm{CN})_{2}^{-a}$ & $1 / 2 \mathrm{~N}(\mathrm{CN}) 2^{-a}$ & $\mathrm{ZnCl}_{2},\left(\mathrm{Ph}_{4} \mathrm{P}\right) \mathrm{N}(\mathrm{CN})_{2}$ & TCE/EtOH(17:1) \\
\hline 7 & $5: 2$ & +0.8 & $\mathrm{Zn}\left[\mathrm{C}(\mathrm{CN})_{3}\right] \mathrm{Br}_{3}{ }^{2-}$ & $\mathrm{Br}^{-}$ & $\mathrm{C}(\mathrm{CN})_{3^{-}}$ & $\mathrm{Br}^{-}$ & $\mathrm{ZnBr} 2,\left(\mathrm{Ph}_{4} \mathrm{P}\right) \mathrm{C}(\mathrm{CN})_{3}$ & TCE/EtOH(17:1) \\
\hline 8 & $3: 2: 2\left(\mathrm{H}_{2} \mathrm{O}\right)$ & +0.67 & $\mathrm{ZnCl}_{3}\left(\mathrm{H}_{2} \mathrm{O}\right)^{-}$ & $\mathrm{Cl}^{-}$ & $\mathrm{Cl}^{-}$ & $\mathrm{H}_{2} \mathrm{O}$ & $\mathrm{ZnCl}_{2}, \mathrm{KCl}, 18 \mathrm{C} 6$ & TCE \\
\hline \multirow[t]{3}{*}{9} & 7:2:2(TCE):1(EtOH) & +0.57 & $\mathrm{ZnBr}_{4}{ }^{2-}$ & $\mathrm{Br}^{-}$ & $\mathrm{Br}^{-}$ & $\mathrm{Br}^{-}$ & $\mathrm{ZnBr} 2, \mathrm{KC}(\mathrm{CN})_{3}, \mathrm{KBr}, 18 \mathrm{C} 6$ & TCE \\
\hline & & & & & & & $\mathrm{ZnBr} 2,(\mathrm{Bu} 4 \mathrm{~N}) \mathrm{Au}(\mathrm{CN})_{2}$ & TCE/EtOH(17:1) \\
\hline & & & & & & & $\mathrm{ZnBr} 2, \mathrm{~KB}(\mathrm{CN})_{4}, \mathrm{KBr}, 18 \mathrm{C} 6$ & TCE/EtOH(17:1) \\
\hline \multicolumn{9}{|c|}{ Group D } \\
\hline \multirow[t]{2}{*}{10} & 4:1:1(TCE) & +0.5 & $\mathrm{Zn}(\mathrm{NCS})_{2} \mathrm{Cl}_{2}{ }^{2-}$ & $\mathrm{SCN}^{-}$ & $\mathrm{Cl}^{-}$ & $\mathrm{Cl}^{-}$ & $\mathrm{Zn}(\mathrm{SCN})_{2}, \mathrm{KSCN}, \mathrm{KCl}, 18 \mathrm{C} 6$ & TCE \\
\hline & & & & & & & $\mathrm{ZnCl}_{2},\left(\mathrm{Ph}_{4} \mathrm{P}\right) \mathrm{SCN},\left(\mathrm{Ph}_{4} \mathrm{P}\right) \mathrm{Cl}$ & TCE \\
\hline 11 & 4:1:1(TCE) & +0.5 & $\mathrm{Zn}(\mathrm{NCS}){ }_{2} \mathrm{Br}_{2}{ }^{2-}$ & $\mathrm{SCN}^{-}$ & $\mathrm{Br}^{-}$ & $\mathrm{Br}^{-}$ & $\mathrm{Zn}(\mathrm{SCN})_{2}, \mathrm{KSCN}, \mathrm{KBr}, 18 \mathrm{C} 6$ & TCE \\
\hline 12 & 4:1:1(TCE) & +0.5 & $\mathrm{Zn}\left[\mathrm{N}(\mathrm{CN})_{2}\right] \mathrm{Cl}_{3}{ }^{2-}$ & $\mathrm{Cl}^{-}$ & $\mathrm{N}(\mathrm{CN})_{2}^{-}$ & $\mathrm{Cl}^{-}$ & $\mathrm{ZnCl}_{2},\left(\mathrm{Ph}_{4} \mathrm{P}\right) \mathrm{N}(\mathrm{CN})_{2}$ & TCE/EtOH(17:1) \\
\hline
\end{tabular}

${ }^{a}$ Dicyanamide anion serves as a bidentate ligand, affording a polymeric structure.

b 18C6: 18-crown-6.

${ }^{c}$ TCE: 1,1,2-trichloroethane.

${ }^{d} \mathrm{~A}$ few drops of $\mathrm{MeOH}$ are added. 
Table 2. Crystallographic data of 1-12

\begin{tabular}{|c|c|c|c|c|}
\hline Salt & 1 & 2 & 3 & 4 \\
\hline Formula & $\mathrm{C}_{24} \mathrm{H}_{16} \mathrm{Cl}_{3} \mathrm{~N}_{3} \mathrm{~S}_{16} \mathrm{Zn}$ & $\mathrm{C}_{24} \mathrm{H}_{16} \mathrm{Br}_{3} \mathrm{~N}_{3} \mathrm{~S}_{16} \mathrm{Zn}$ & $\mathrm{C}_{22} \mathrm{H}_{16} \mathrm{AuCl}_{3} \mathrm{~N}_{2} \mathrm{~S}_{16} \mathrm{Zn}$ & $\mathrm{C}_{23} \mathrm{H}_{19} \mathrm{AuBr}_{3} \mathrm{~N}_{2} \mathrm{O}_{0.5} \mathrm{~S}_{16} \mathrm{Zn}$ \\
\hline Formula weight & 1031.22 & 1164.57 & 1190.15 & 1346.54 \\
\hline Crystal system & Monoclinic & Monoclinic & Monoclinic & Triclinic \\
\hline Space group & $P 2{ }_{1} / c$ & $P 2{ }_{1} / n$ & $P 2_{1} / c$ & $P \overline{1}$ \\
\hline Crystal size, $\mathrm{mm}^{3}$ & $0.50 \times 0.09 \times 0.06$ & $0.50 \times 0.08 \times 0.05$ & $0.43 \times 0.34 \times 0.16$ & $0.47 \times 0.22 \times 0.08$ \\
\hline$a, \AA$ & $8.6618(7)$ & $7.9518(6)$ & $16.241(1)$ & $14.092(1)$ \\
\hline$b, \AA$ & 13.299(1) & $14.013(1)$ & 14.699(1) & $15.807(1)$ \\
\hline$c, \AA$ & $31.576(3)$ & 32.938(3) & $15.698(1)$ & 17.101(1) \\
\hline$\alpha$, deg & 90 & 90 & 90 & $90.796(1)$ \\
\hline$\beta$, deg & $95.727(1)$ & $90.679(1)$ & $104.540(1)$ & $92.707(1)$ \\
\hline$\gamma, \operatorname{deg}$ & 90 & 90 & 90 & 91.113(1) \\
\hline$V, \AA^{3}$ & $3619.2(5)$ & $3669.9(5)$ & $3627.5(4)$ & 3803.8(5) \\
\hline Z & 4 & 4 & 4 & 4 \\
\hline Temperature, K & 100 & 100 & 100 & 100 \\
\hline$d_{\mathrm{alc}}, \mathrm{g} \mathrm{cm}^{-3}$ & 1.892 & 2.108 & 2.179 & 2.365 \\
\hline$\mu(\mathrm{Mo} \mathrm{K} \alpha), \mathrm{mm}^{-1}$ & 1.851 & 4.874 & 5.867 & 8.541 \\
\hline Reflns used & 7383 & 7498 & 7391 & 15056 \\
\hline Refined params & 460 & 424 & 406 & 869 \\
\hline$R_{1}(\text { for } I>2 \sigma(I))^{a}$ & 0.0328 & 0.0224 & 0.0160 & 0.0221 \\
\hline$w R_{2}$ (for all data) $)^{b}$ & 0.0725 & 0.0637 & 0.0401 & 0.0559 \\
\hline GOF on $F^{2}$ & 1.045 & 1.096 & 1.042 & 1.052 \\
\hline CCDC number & 1482867 & 1482868 & 1482869 & 1482870 \\
\hline
\end{tabular}

\begin{tabular}{|c|c|c|c|c|}
\hline Salt & 4 & 5 & 6 & 7 \\
\hline Formula & $\mathrm{C}_{23} \mathrm{H}_{19} \mathrm{AuBr}_{3} \mathrm{~N}_{2} \mathrm{O}_{0.5} \mathrm{~S}_{16} \mathrm{Zn}$ & $\mathrm{C}_{28} \mathrm{H}_{16} \mathrm{Br}_{2} \mathrm{~N}_{6} \mathrm{~S}_{16} \mathrm{Zn}_{1}$ & $\mathrm{C}_{23} \mathrm{H}_{17.5} \mathrm{Cl}_{3.5} \mathrm{~N}_{3} \mathrm{~S}_{16} \mathrm{Zn}$ & $\mathrm{C}_{58} \mathrm{H}_{40} \mathrm{Br}_{6} \mathrm{~N}_{6} \mathrm{~S}_{40} \mathrm{Zn}_{2}$ \\
\hline Formula weight & 1346.54 & 1174.73 & 1038.44 & 2713.84 \\
\hline Crystal system & Monoclinic & Triclinic & Triclinic & Triclinic \\
\hline Space group & $P 2_{1} / c$ & $P \overline{1}$ & $P \overline{1}$ & $P \overline{1}$ \\
\hline Crystal size, $\mathrm{mm}^{3}$ & $0.47 \times 0.22 \times 0.08$ & $0.21 \times 0.08 \times 0.06$ & $0.50 \times 0.31 \times 0.05$ & $0.33 \times 0.28 \times 0.05$ \\
\hline$a, \AA$ & $17.100(1)$ & $5.7615(6)$ & $6.8149(5)$ & $9.926(1)$ \\
\hline$b, \AA$ & $14.234(1)$ & $12.654(1)$ & $15.000(1)$ & $14.048(2)$ \\
\hline$c, \AA$ & 16.112(1) & 13.940(1) & $18.739(1)$ & $32.576(4)$ \\
\hline$\alpha$, deg & 90 & $84.132(1)$ & 101.136(1) & $99.493(2)$ \\
\hline$\beta$, deg & $90.854(1)$ & 86.201(1) & $96.536(1)$ & $96.183(1)$ \\
\hline$\gamma, \operatorname{deg}$ & 90 & $80.312(1)$ & $99.158(1)$ & $91.270(2)$ \\
\hline$V, \AA^{3}$ & 3921.3(6) & $995.3(2)$ & $1834.8(2)$ & $4450.5(9)$ \\
\hline Z & 4 & 1 & 2 & 2 \\
\hline Temperature, K & 298 & 100 & 100 & 100 \\
\hline$d_{\mathrm{alc}}, \mathrm{g} \mathrm{cm}^{-3}$ & 2.294 & 1.960 & 1.879 & 2.025 \\
\hline$\mu(\mathrm{Mo} \mathrm{K} \alpha), \mathrm{mm}^{-1}$ & 8.285 & 3.499 & 1.862 & 4.216 \\
\hline Reflns used & 7991 & 4050 & 6910 & 17553 \\
\hline Refined params & 479 & 290 & 442 & 1046 \\
\hline$R_{1}(\text { for } I>2 \sigma(I))^{a}$ & 0.0260 & 0.0577 & 0.0699 & 0.0626 \\
\hline$w R_{2}$ (for all data) ${ }^{b}$ & 0.0742 & 0.1141 & 0.1830 & 0.1662 \\
\hline GOF on $F^{2}$ & 1.063 & 1.274 & 1.026 & 1.013 \\
\hline CCDC number & 1482871 & 1482872 & 1482873 & 1482874 \\
\hline
\end{tabular}


Table 2. Continued

\begin{tabular}{|c|c|c|c|c|}
\hline Salt & 8 & 9 & 9 & 10 \\
\hline Formula & $\mathrm{C}_{30} \mathrm{H}_{32} \mathrm{Cl}_{6} \mathrm{O}_{4} \mathrm{~S}_{24} \mathrm{Zn}_{2}$ & $\mathrm{C}_{76} \mathrm{H}_{68} \mathrm{Br}_{8} \mathrm{Cl}_{6} \mathrm{OS}_{56} \mathrm{Zn}_{2}$ & $\mathrm{C}_{76} \mathrm{H}_{68} \mathrm{Br}_{8} \mathrm{Cl}_{6} \mathrm{OSS}_{56} \mathrm{Zn}_{2}$ & $\mathrm{C}_{44} \mathrm{H}_{35} \mathrm{Cl}_{5} \mathrm{~N}_{2} \mathrm{~S}_{34} \mathrm{Zn}$ \\
\hline Formula weight & 1569.66 & 3775.80 & 3775.80 & 1924.67 \\
\hline Crystal system & Monoclinic & Monoclinic & Monoclinic & Monoclinic \\
\hline Space group & $P 2{ }_{1} / n$ & $P 2{ }_{1} / c$ & $P 2_{1} / c$ & $C 2 / m$ \\
\hline Crystal size, $\mathrm{mm}^{3}$ & $0.41 \times 0.33 \times 0.04$ & $0.45 \times 0.38 \times 0.10$ & $0.45 \times 0.38 \times 0.10$ & $0.43 \times 0.34 \times 0.16$ \\
\hline$a, \AA$ & $7.746(1)$ & $18.856(2)$ & $18.964(2)$ & $16.644(2)$ \\
\hline$b, \AA$ & $37.331(5)$ & $11.538(1)$ & 11.5823(9) & $37.220(5)$ \\
\hline$c, \AA$ & $9.569(1)$ & 28.224(3) & 28.921(2) & $11.876(2)$ \\
\hline$\alpha$, deg & 90 & 90 & 90 & 90 \\
\hline$\beta$, deg & $97.723(2)$ & $96.873(1)$ & $97.258(1)$ & $110.825(1)$ \\
\hline$\gamma, \operatorname{deg}$ & 90 & 90 & 90 & 90 \\
\hline$V, \AA^{3}$ & $2741.6(6)$ & $6096(1)$ & $6301.5(8)$ & $6876(2)$ \\
\hline$Z$ & 2 & 2 & 2 & 4 \\
\hline Temperature, K & 298 & 100 & 298 & 100 \\
\hline$d_{\mathrm{alc}}, \mathrm{g} \mathrm{cm}^{-3}$ & 1.901 & 2.057 & 1.990 & 1.859 \\
\hline$\mu(\mathrm{Mo} \mathrm{K} \alpha), \mathrm{mm}^{-1}$ & 2.119 & 4.151 & 4.016 & 1.623 \\
\hline Reflns used & 5563 & 12313 & 12856 & 7062 \\
\hline Refined params & 345 & 686 & 725 & 472 \\
\hline$R_{1}(\text { for } I>2 \sigma(I))^{a}$ & 0.0581 & 0.0501 & 0.0535 & 0.0619 \\
\hline$w R_{2}$ (for all data) ${ }^{b}$ & 0.1321 & 0.0991 & 0.1500 & 0.1942 \\
\hline GOF on $F^{2}$ & 1.257 & 1.136 & 1.035 & 1.160 \\
\hline CCDC number & 1482875 & 1482876 & 1482877 & 1482878 \\
\hline
\end{tabular}

\begin{tabular}{|c|c|c|c|c|}
\hline Salt & 10 & 11 & 11 & 12 \\
\hline Formula & $\mathrm{C}_{44} \mathrm{H}_{35} \mathrm{Cl}_{5} \mathrm{~N}_{2} \mathrm{~S}_{34} \mathrm{Zn}$ & $\mathrm{C}_{44} \mathrm{H}_{35} \mathrm{Br}_{2} \mathrm{Cl}_{3} \mathrm{~N}_{2} \mathrm{~S}_{34} \mathrm{Zn}$ & $\mathrm{C}_{44} \mathrm{H}_{35} \mathrm{Br}_{2} \mathrm{Cl}_{3} \mathrm{~N}_{2} \mathrm{~S}_{34} \mathrm{Zn}$ & $\mathrm{C}_{44} \mathrm{H}_{35} \mathrm{Cl}_{6} \mathrm{~N}_{3} \mathrm{~S}_{32} \mathrm{Zn}$ \\
\hline Formula weight & 1924.67 & 2013.58 & 2013.58 & 1909.74 \\
\hline Crystal system & Monoclinic & Monoclinic & Monoclinic & Monoclinic \\
\hline Space group & $C 2 / m$ & $C 2 / c$ & $C 2 / m$ & $P 2_{1} / n$ \\
\hline Crystal size, $\mathrm{mm}^{3}$ & $0.43 \times 0.34 \times 0.16$ & $0.49 \times 0.19 \times 0.07$ & $0.49 \times 0.19 \times 0.07$ & $0.25 \times 0.18 \times 0.04$ \\
\hline$a, \AA$ & $17.134(2)$ & $16.875(2)$ & $17.172(2)$ & $11.635(1)$ \\
\hline$b, \AA$ & $37.241(5)$ & $37.275(4)$ & $37.422(4)$ & $37.122(4)$ \\
\hline$c, \AA$ & $11.928(2)$ & 23.421(3) & $11.975(1)$ & $16.871(2)$ \\
\hline$\alpha$, deg & 90 & 90 & 90 & 90 \\
\hline$\beta$, deg & 111.351(1) & 110.162(1) & 111.639(1) & $110.148(1)$ \\
\hline$\gamma, \operatorname{deg}$ & 90 & 90 & 90 & 90 \\
\hline$V, \AA^{3}$ & $7088(2)$ & 13829(3) & 7153(1) & $6841(1)$ \\
\hline Z & 4 & 8 & 4 & 4 \\
\hline Temperature, K & 298 & 100 & 298 & 100 \\
\hline$d_{\mathrm{alc}}, \mathrm{g} \mathrm{cm}^{-3}$ & 1.803 & 1.934 & 1.869 & 1.854 \\
\hline$\mu(\mathrm{Mo} \mathrm{K} \alpha), \mathrm{mm}^{-1}$ & 1.575 & 2.693 & 2.603 & 1.610 \\
\hline Reflns used & 7277 & 14123 & 7378 & 9812 \\
\hline Refined params & 491 & 852 & 507 & 859 \\
\hline$R_{1}(\text { for } I>2 \sigma(I))^{a}$ & 0.0649 & 0.0640 & 0.0484 & 0.0755 \\
\hline$w R_{2}$ (for all data) ${ }^{b}$ & 0.2223 & 0.1855 & 0.1773 & 0.2315 \\
\hline GOF on $F^{2}$ & 1.107 & 1.109 & 1.040 & 1.026 \\
\hline CCDC number & 1482879 & 1482880 & 1482881 & 1482882 \\
\hline
\end{tabular}


Table 2. Continued

\begin{tabular}{|c|c|}
\hline Salt & 12 \\
\hline Formula & $\mathrm{C}_{44} \mathrm{H}_{35} \mathrm{Cl}_{6} \mathrm{~N}_{3} \mathrm{~S}_{32} \mathrm{Zn}$ \\
\hline Formula weight & 1909.74 \\
\hline Crystal system & Monoclinic \\
\hline Space group & $C 2 / m$ \\
\hline Crystal size, $\mathrm{mm}^{3}$ & $0.25 \times 0.18 \times 0.04$ \\
\hline$a, \AA$ & $17.259(1)$ \\
\hline$b, \AA$ & 37.155(3) \\
\hline$c, \AA$ & $11.736(1)$ \\
\hline$\alpha, \operatorname{deg}$ & 90 \\
\hline$\beta$, deg & 110.831(1) \\
\hline$\gamma, \operatorname{deg}$ & 90 \\
\hline$V, \AA^{3}$ & 7034(1) \\
\hline$Z$ & 4 \\
\hline Temperature, K & 298 \\
\hline$d_{\mathrm{alc}}, \mathrm{g} \mathrm{cm}^{-3}$ & 1.803 \\
\hline$\mu(\mathrm{Mo} \mathrm{K} \alpha), \mathrm{mm}^{-1}$ & 1.566 \\
\hline Reflns used & 7324 \\
\hline Refined params & 459 \\
\hline$R_{1}(\text { for } I>2 \sigma(I))^{a}$ & 0.0493 \\
\hline$w R_{2}$ (for all data) ${ }^{b}$ & 0.1461 \\
\hline GOF on $F^{2}$ & 1.035 \\
\hline CCDC number & 1482883 \\
\hline
\end{tabular}

${ }^{a} R_{1}=\Sigma\left(\left|F_{0}\right|-\left|F_{\mathrm{c}}\right|\right) / \Sigma\left|F_{0}\right|{ }^{b} w R_{2}=\left[\Sigma w\left(F_{0}{ }^{2}-F_{\mathrm{c}}{ }^{2}\right)^{2} / \Sigma w\left(F_{0}^{2}\right)^{2}\right]^{0.5}$. 
Table 3. Structural and physical properties of 10-12

\begin{tabular}{llll}
\hline Salt & $\mathbf{1 0}$ & $\mathbf{1 1}$ & $\mathbf{1 2}$ \\
\hline charge $^{a}$ & $\underline{298 \mathrm{~K}}$ & $\underline{298 \mathrm{~K}}$ & $\underline{298 \mathrm{~K}}$ \\
& $+0.65(8),+0.65(7)$ & $+0.58(7),+0.59(6)$ & $+0.78(5),+0.61(5)$ \\
& $\underline{100 \mathrm{~K}}$ & $\underline{100 \mathrm{~K}}$ & $\underline{100 \mathrm{~K}}$ \\
& $+0.60(8),+0.58(7)$ & $+0.49(8),+0.63(9)$, & $+0.54(13),+0.40(13)$, \\
& & $+0.40(8),+0.44(9)$ & $+0.87(14),+0.23(13)$ \\
$a c \sin \beta, \AA^{2 b}$ & 190.3 & 191.2 & 189.3 \\
$\theta,{ }^{\circ} \mathrm{c}$ & 127.6 & 128.1 & 124.9 \\
$W, \mathrm{eV}^{d}$ & 0.876 & 0.864 & 0.947 \\
$\sigma, \mathrm{S} \mathrm{cm}^{-1 e}$ & 2.7 & 1.5 & 4.8 \\
$E_{\mathrm{a}}, \mathrm{eV}^{f}$ & $0.18(T<170 \mathrm{~K})$ & $0.17(T<160 \mathrm{~K})$ & $0.13(T<190 \mathrm{~K})$ \\
& $0.19(T>250 \mathrm{~K})$ & $0.15(T>240 \mathrm{~K})$ & $0.11(T>270 \mathrm{~K})$ \\
$T_{0}, \mathrm{~K}^{g}$ & 210,224 & 200,189 & 230,253 \\
$J / k_{\mathrm{B}}, \mathrm{K}^{h}$ & 54.7 & 85.4 & 47.2 \\
$f^{i}$ & 0.880 & 0.835 & 0.842 \\
\hline
\end{tabular}

${ }^{a}$ Estimated on the basis of bond length analysis. ${ }^{32}$

${ }^{b}$ Unit area of the ET layer estimated on the basis of X-ray diffraction data at $298 \mathrm{~K}$.

${ }^{c}$ Dihedral angle between the planes of ET molecules in adjacent columns.

${ }^{d}$ Bandwidth of the HOMO band calculated on the basis of the extended Hückel method with the tight-binding approximation using crystallographic data at $298 \mathrm{~K}$.

e Conductivity at RT.

$f$ Activation energy for conduction.

${ }^{g}$ Critical temperatures estimated from the temperature dependence of resistivity and superlattice reflections (see text for details).

${ }^{h}$ Exchange interaction estimated on the basis of the $S=1 / 2$ Heisenberg AF linear chain model (Eq. 1').

${ }^{i}$ Fraction of uncorrelated Curie component (Eq. 1). 
(a)

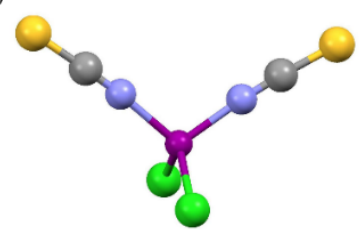

$\mathrm{Zn}(\mathrm{NCS}){ }_{2} \mathrm{Cl}_{2}{ }^{2-}$

(c)

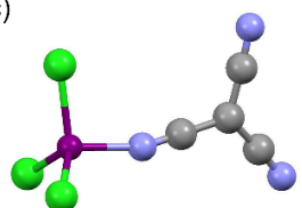

$\mathrm{Zn}\left[\mathrm{C}(\mathrm{CN})_{3}\right] \mathrm{Cl}_{3}{ }^{2-}$ (b)

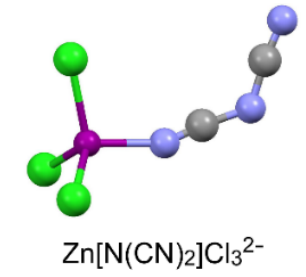

(d)

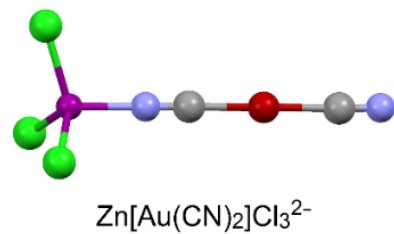

Figure 1. Crystallographically characterized (a) $\mathrm{Zn}(\mathrm{NCS})_{2} \mathrm{Cl}_{2}{ }^{2-}$ (in 10), (b) $\mathrm{Zn}\left[\mathrm{N}(\mathrm{CN})_{2}\right] \mathrm{Cl}_{3}{ }^{2-}$ (in 12), (c) $\mathrm{Zn}\left[\mathrm{C}(\mathrm{CN})_{3}\right] \mathrm{Cl}_{3}{ }^{2-}$ (in 1) and (d) $\mathrm{Zn}\left[\mathrm{Au}(\mathrm{CN})_{2}\right] \mathrm{Cl}_{3}{ }^{2-}$ (in 3) ions, where grey, blue, yellow, green, red, and purple spheres indicate $\mathrm{C}, \mathrm{N}, \mathrm{S}, \mathrm{Cl}, \mathrm{Au}$, and $\mathrm{Zn}$ atoms, respectively. 


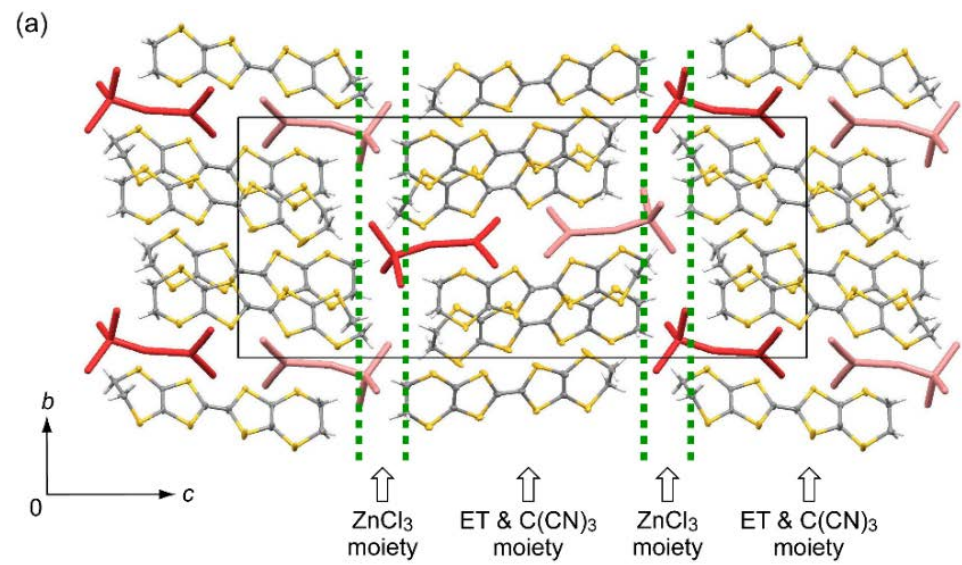

(b)

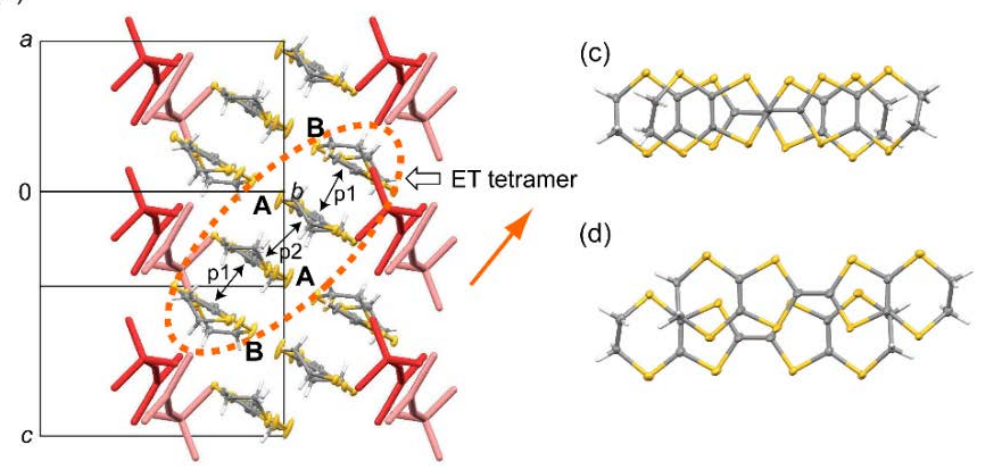

Figure 2. Crystal structure of $(\mathrm{ET})_{2} \mathrm{Zn}\left[\mathrm{C}(\mathrm{CN})_{3}\right] \mathrm{Cl}_{3}$ (1) viewed along (a) the $a$ axis and (b) the long axis of ET molecules. $\mathrm{Zn}\left[\mathrm{C}(\mathrm{CN})_{3}\right] \mathrm{Br}_{3}{ }^{2-}$ ions at a lower and higher $\mathrm{z}$ value among a dimer are indicated in red and pink, respectively. Green dotted lines in (a) indicating the boundary are guides to the eyes. In (b), an orange dotted ellipse indicates the ET tetramer, and an orange arrow indicates the $2 a+b$ direction. The overlap integrals $\left(\times 10^{-3}\right)$ are $\mathrm{p} 1=-$ 28.2 and p2 $=-4.8$. See text for $\mathbf{A}$ and $\mathbf{B}$. (c) Ring-over-bond-type and (d) ring-over-atom-type overlap patterns of adjacent ET molecules between $\mathbf{A}$ and $\mathbf{B}$ and between $\mathbf{A}$ and $\mathbf{A}$, respectively. 

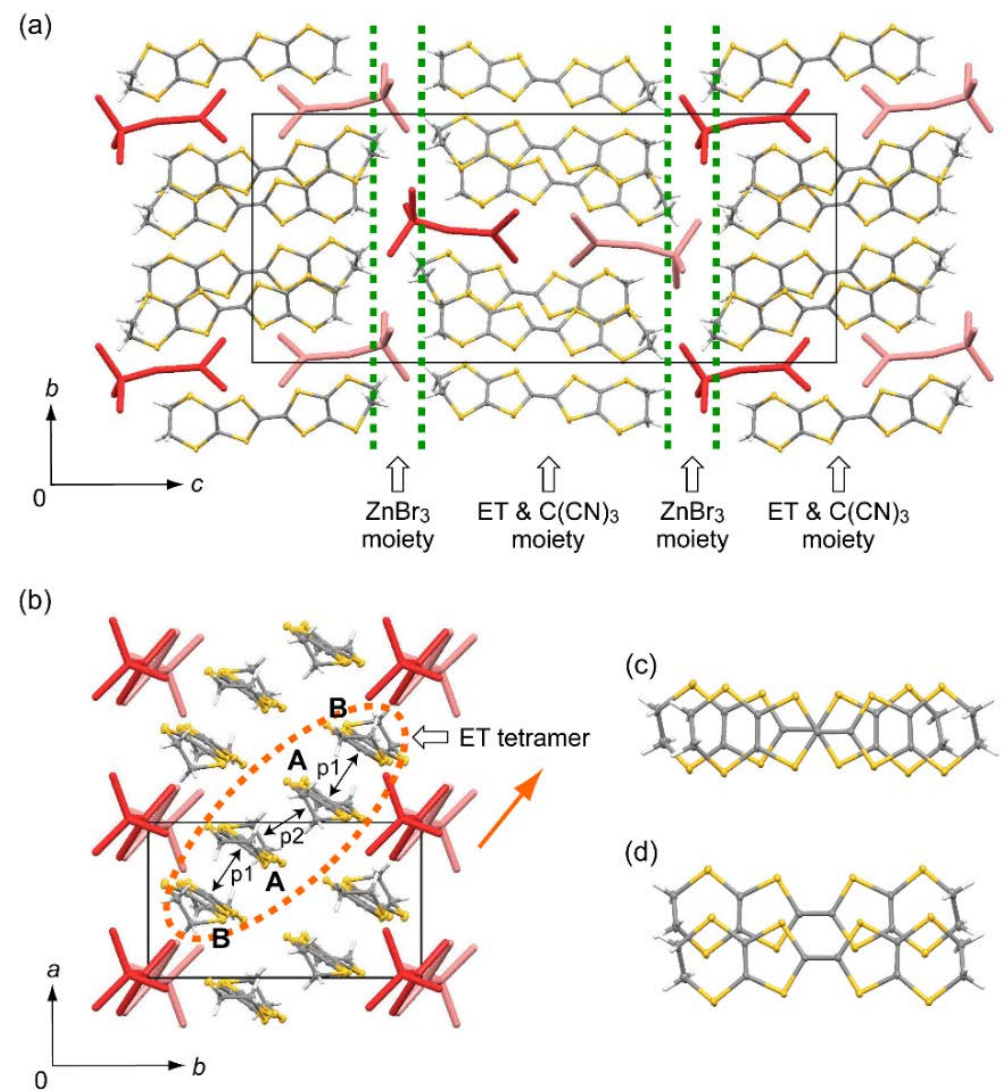

(c)

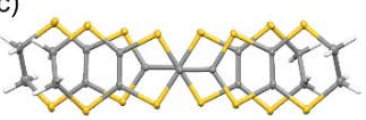

(d)

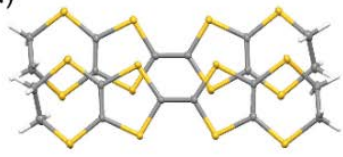

Figure 3. Crystal structure of $(\mathrm{ET})_{2} \mathrm{Zn}\left[\mathrm{C}(\mathrm{CN})_{3}\right] \mathrm{Br}_{3}$ (2) viewed along (a) the $a$ axis and (b) the $c$ axis. $\mathrm{Zn}\left[\mathrm{C}(\mathrm{CN})_{3}\right] \mathrm{Br}_{3}{ }^{2-}$ ions at lower and higher $\mathrm{z}$ values among a dimer are indicated in red and pink, respectively. Green dotted lines in (a) indicating the boundary are guides to the eyes. In (b), an orange dotted ellipse indicates the ET tetramer, and an orange arrow indicates the $2 a+b$ direction. The overlap integrals $\left(\times 10^{-3}\right)$ are $\mathrm{p} 1=-29.0$ and $\mathrm{p} 2=-0.2$. See text for A and B. (c) Ring-over-bond-type and (d) ring-over-atom-type overlap patterns of adjacent ET molecules between $\mathbf{A}$ and $\mathbf{B}$ and between $\mathbf{A}$ and $\mathbf{A}$, respectively. 
(a)

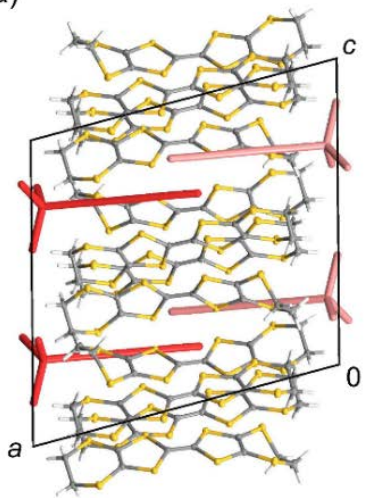

(c)

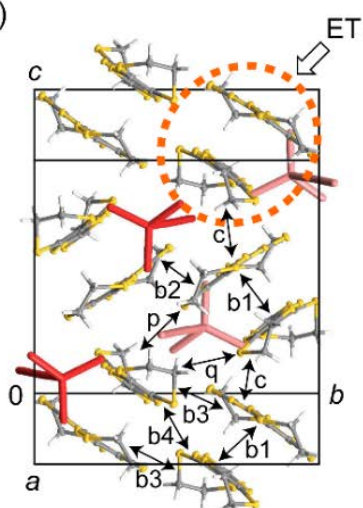

(b)

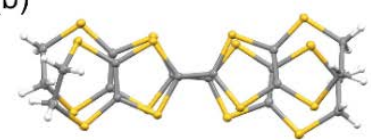

(d)

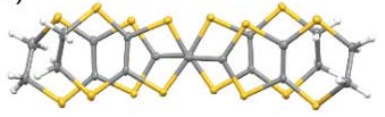

(e)

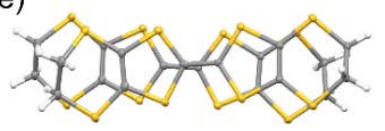

Figure 4. (a) Crystal structure of $(\mathrm{ET})_{2} \mathrm{Zn}\left[\mathrm{Au}(\mathrm{CN})_{2}\right] \mathrm{Cl}_{3}$ (3) viewed along the $b$ axis. $\mathrm{Zn}\left[\mathrm{Au}(\mathrm{CN})_{2}\right] \mathrm{Cl}_{3}{ }^{2-}$ ions with zinc(II) at $x \sim 1$ and 0 are drawn in red and pink, respectively. (b) Overlap pattern of ET molecules within the dimer in 3. (c) Crystal structure of 3 viewed along the molecular long axis of ET, where an orange dotted ellipse shows the $(\mathrm{ET})_{2}{ }^{2+}$ dimer (left panel). The overlap integrals $\left(\times 10^{-3}\right)$ are b1 $=41.4$, b2 $=21.4$, b3 $=-6.5$, b4 $=-4.1, \mathrm{c}=$ 14.7, $\mathrm{p}=0.2$, and $\mathrm{q}=0.2$. Schematic of $\kappa$-like packing based on $(\mathrm{ET})_{2}{ }^{2+}$ dimers (orange circles), where cross marks indicate $\mathrm{Zn}\left[\mathrm{Au}(\mathrm{CN})_{2}\right] \mathrm{Cl}_{3}{ }^{2-}$ ions and inter-dimer transfer integrals (meV) are $t_{1}=73.5 t_{2}=96.3$, and $t_{3}=1.7$ (right panel). (d,e) Overlap patterns of ET molecules within the dimers in $(\mathrm{ET})_{2} \mathrm{Zn}\left[\mathrm{Au}(\mathrm{CN})_{2}\right] \mathrm{Br}_{3}(\mathrm{EtOH})_{0.5}(\mathbf{4})$. 
(a)

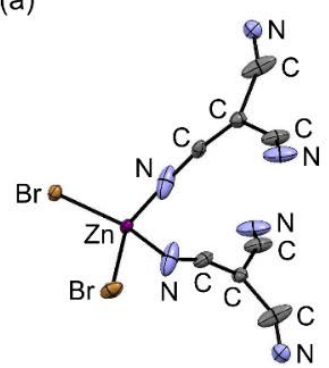

(b)

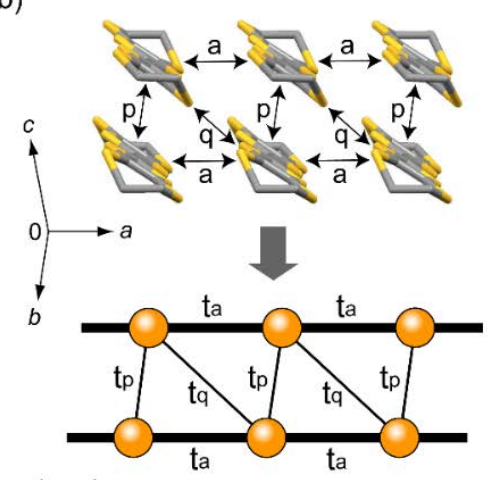

(c)

disordered

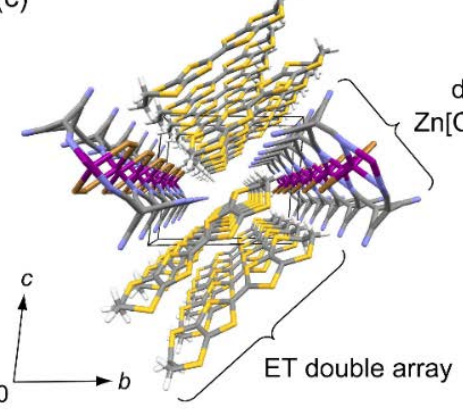

$\mathrm{Zn}\left[\mathrm{C}(\mathrm{CN})_{3}\right]_{2} \mathrm{Br}_{2}{ }^{2-}$

(d)

(e)
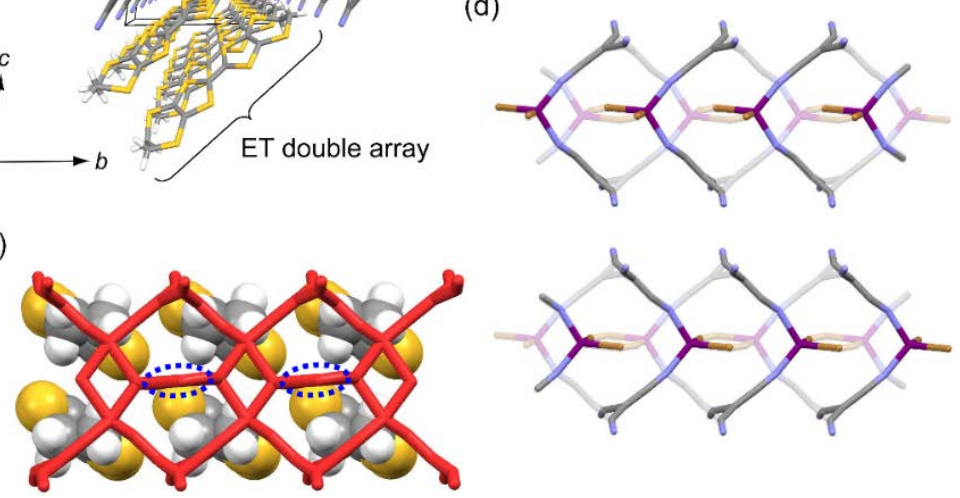

Figure 5. (a) Molecular structure of $\mathrm{Zn}\left[\mathrm{C}(\mathrm{CN})_{3}\right]_{2} \mathrm{Br}_{2}{ }^{-}$ion in $(\mathrm{ET})_{2} \mathrm{Zn}\left[\mathrm{C}(\mathrm{CN})_{3}\right]_{2} \mathrm{Br}_{2}$ (5). (b) Molecular arrangement of ET molecules in $\mathbf{5}$ and the schematic zig-zag chain based on ET ${ }^{\bullet+}$ (orange circles), where overlap integrals $\left(\times 10^{-3}\right)$ are $\mathrm{a}=-21.6, \mathrm{p}=-5.5$, and $\mathrm{q}=-6.2$ and transfer integrals (meV) are $t_{\mathrm{a}}=216, t_{\mathrm{p}}=54.9$, and $t_{\mathrm{q}}=62.2 \mathrm{meV}$. (c) A perspective view along the $a$ axis. (d) Arrangement of positionally disordered $\mathrm{Zn}\left[\mathrm{C}(\mathrm{CN})_{3}\right]_{2} \mathrm{Br}_{2}{ }^{2-}$ ions to show the formation of the pseudo-polymeric chain along the $a$ axis, where the orientation of crystallographic axes is essentially the same as that in (b). (e) Relative arrangement of $\mathrm{ET}^{\bullet+}$ molecules with respect to the pseudo-polymeric chain of $\mathrm{Zn}\left[\mathrm{C}(\mathrm{CN})_{3}\right]_{2} \mathrm{Br}_{2}{ }^{2-}$ ions, where bromide sites enclosed by blue dotted ellipses protrude toward the ET layers of both sides. 


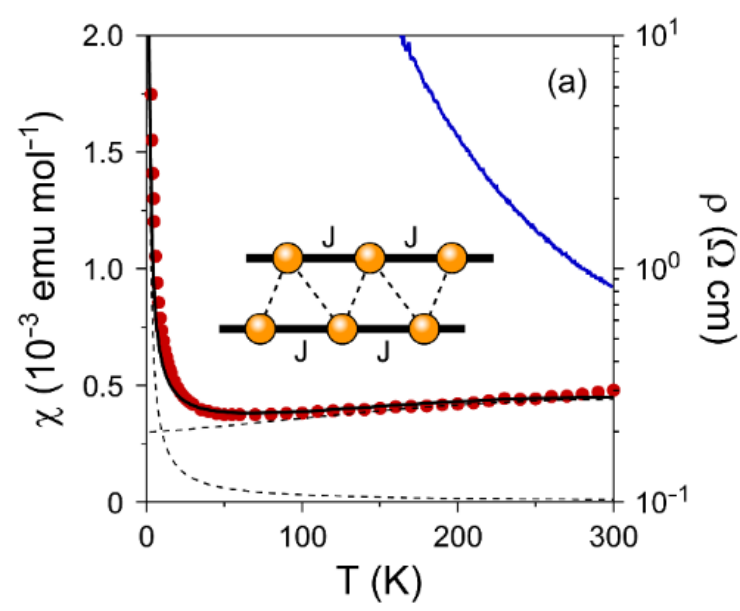

(b)

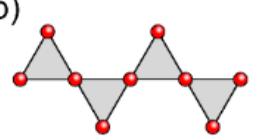

(c)

(d)
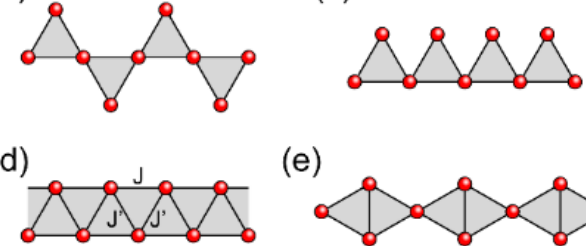

(e)

(f)
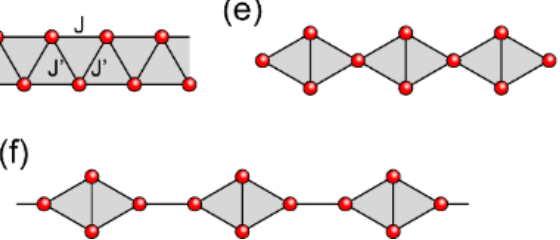

Figure 6. (a) Temperature dependence of resistivity $(\rho)$ of a single crystal of 5 (blue solid line) and static magnetic susceptibility $(\chi)$ of polycrystalline 5 in an applied magnetic field of $1 \mathrm{~T}$ (red circles). Two dotted lines showing divergence at low temperatures and a gradual decrease with decreasing temperature represent the calculated susceptibilities for the Heisenberg AF linear chain model $\left(\mathrm{J} / \mathrm{k}_{\mathrm{B}}=250 \mathrm{~K}\right)^{58,59}$ and for the Curie model (Curie constant $C^{\prime}=3 \times 10^{-3}$ emu $\mathrm{K} \mathrm{mol}^{-1}$ ), respectively. Black solid lines indicate the fitting results, which comprise each of the two components. Schematics of (b) corner-sharing-triangular, (c) sawtooth, (d) zig-zag, (e) diamond, and (f) orthogonal-dimer chains, where red circles indicate the $S=1 / 2$ spin sites. 
(a)

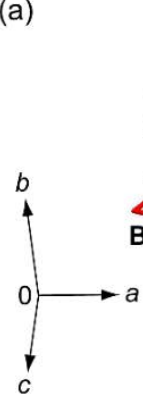

(c)

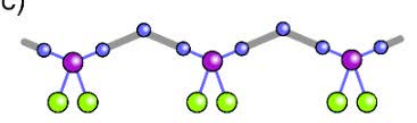

(d)

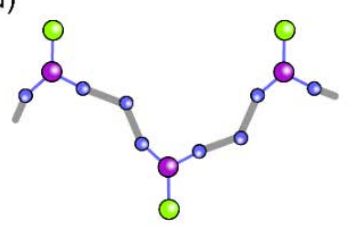

(b)

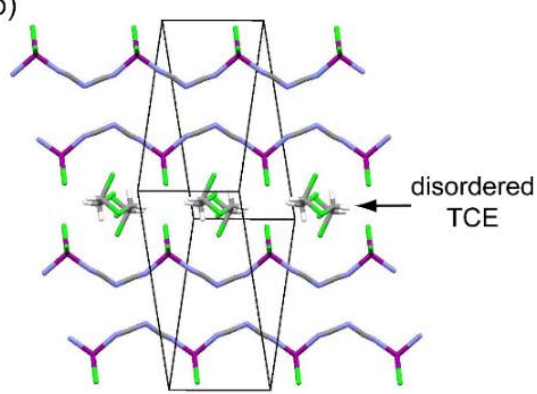

(e)

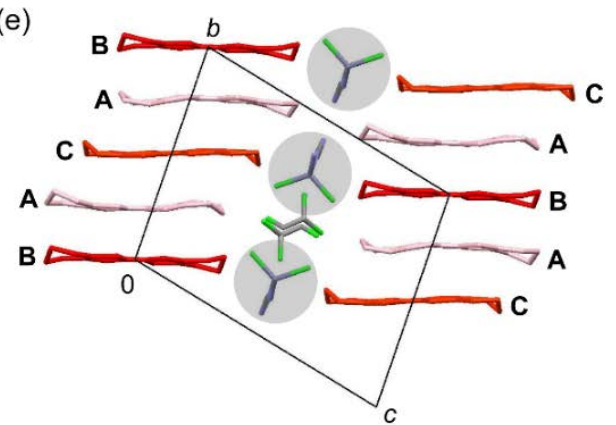

Figure 7. Molecular arrangement within the $a b$ plane for (a) ET molecules at $z \sim 0$ and (b) anion and TCE molecules at $z \sim 0.5$ in $(\mathrm{ET})_{2} \mathrm{Zn}\left[\mathrm{N}(\mathrm{CN})_{2}\right] \mathrm{Cl}_{2}(\mathrm{TCE})_{0.5}(\mathbf{6})$. Hydrogen atoms of ET are omitted for clarity. Charge-rich (B and C) and charge-poor (A) ET molecules are indicated in red and pink, respectively. Schematic structures of polymeric chains of (c) $\left\{\mathrm{Zn}\left[\mathrm{N}(\mathrm{CN})_{2}\right] \mathrm{Cl}_{2}^{-}\right\}_{\infty}$ with the 'in-phase' orientation of $\mathrm{N}(\mathrm{CN})_{2}{ }^{-}$in $\mathbf{6}$ and (d) $\left\{\mathrm{Cu}\left[\mathrm{N}(\mathrm{CN})_{2}\right] \mathrm{Cl}^{-}\right\}_{\infty}$ with the 'out-of-phase' orientation of $\mathrm{N}(\mathrm{CN})_{2}{ }^{-}$in $\kappa-(\mathrm{ET})_{2} \mathrm{Cu}\left[\mathrm{N}(\mathrm{CN})_{2}\right] \mathrm{Cl}$ (thick grey bar: $\mathrm{C}$, greenish yellow: $\mathrm{Cl}$, blue: $\mathrm{N}$, purple: $\mathrm{Zn} / \mathrm{Cu}$ ). (e) Crystal structure of 6 viewed along the $a$ axis, where the $\left\{\mathrm{Zn}\left[\mathrm{N}(\mathrm{CN})_{2}\right] \mathrm{Cl}_{2}{ }^{-}\right\}_{\infty}$ chains are indicated by grey circles. 
(a)

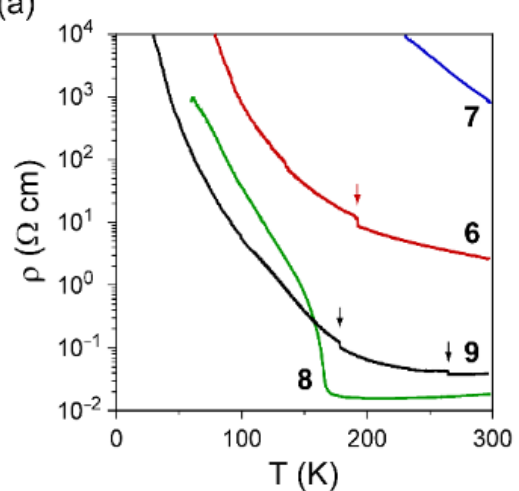

(b)

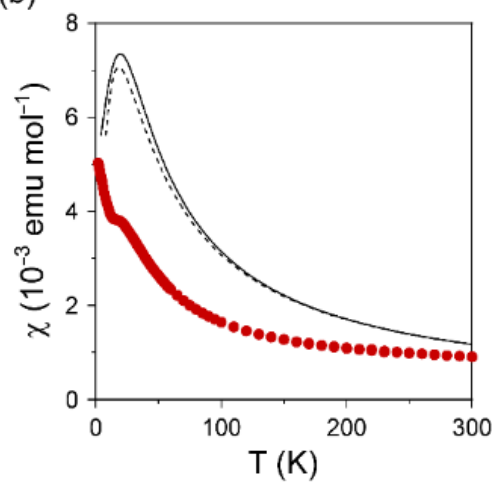

Figure 8. (a) Temperature dependence of $\rho$ of a single crystal of ET salts in Group C (6-9) during the cooling process. Arrows indicate the resistivity jump due to microcrack opening. (b) Temperature dependence of $\chi$ of polycrystalline $\mathbf{6}$ in an applied magnetic field of $1 \mathrm{~T}$. Solid and dotted lines represent the calculated susceptibilities for the $S=1 / 2$ Heisenberg AF linear chain $\left(J / k_{\mathrm{B}}=15 \mathrm{~K}\right)^{58,59}$ and square lattice $\left(\mathrm{J} / \mathrm{k}_{\mathrm{B}}=10 \mathrm{~K}\right),{ }^{62}$ respectively. 
(a)

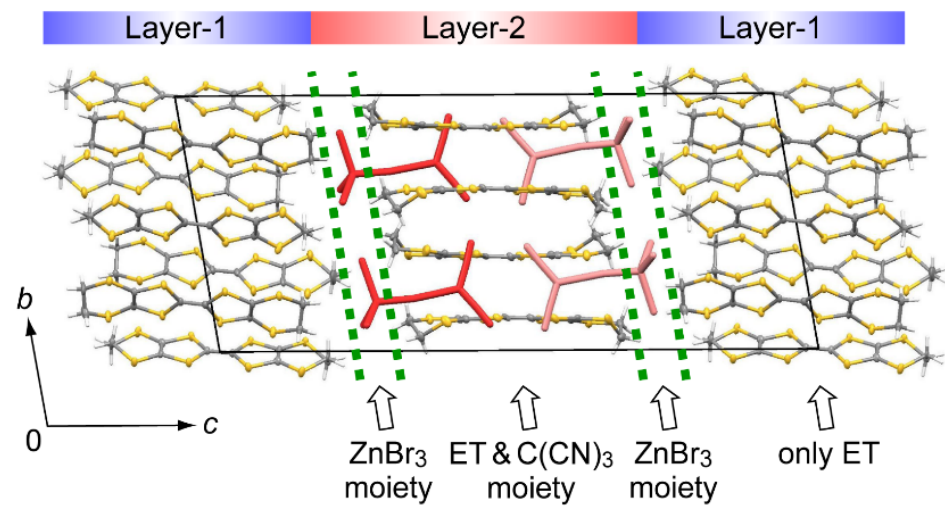

(b)

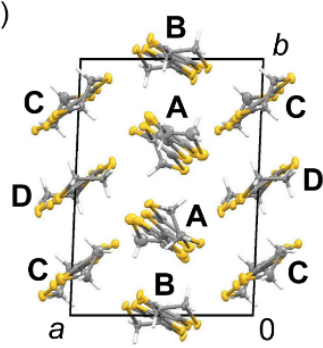

(c)

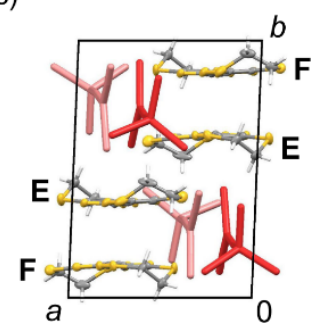

Figure 9. (a) Crystal structure of $(\mathrm{ET})_{5}\left\{\mathrm{Zn}\left[\mathrm{C}(\mathrm{CN})_{3}\right] \mathrm{Br}_{3}\right\}_{2}$ (7) viewed along the $b$ axis. $\mathrm{Zn}\left[\mathrm{C}(\mathrm{CN})_{3}\right] \mathrm{Br}_{3}{ }^{2-}$ ions at lower and higher $\mathrm{z}$ values among a dimer are indicated in red and pink, respectively. Green dotted lines in (a) indicating the boundary are guides to the eyes. Molecular arrangement of (b) ET molecules within the $a b$ plane at $z \sim 0$ (Layer-1) and (c) ET and $\mathrm{Zn}\left[\mathrm{C}(\mathrm{CN})_{3}\right] \mathrm{Br}_{3}{ }^{2-}$ within the $a b$ plane at $\mathrm{z} \sim 0.5$ (Layer-2). See text for $\mathbf{A}-\mathbf{F}$. 
(a)

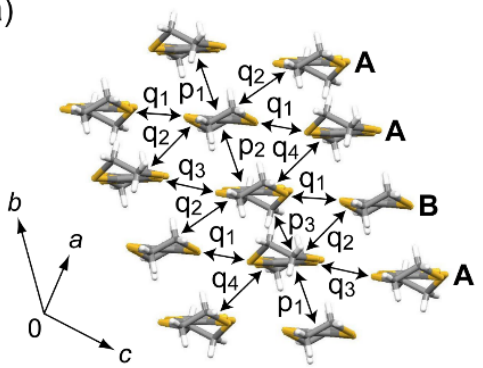

(b)

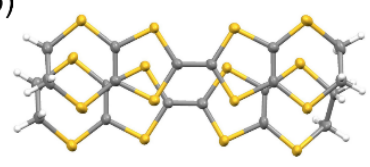

(c)

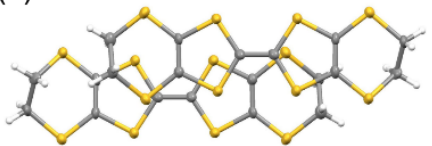

(d)

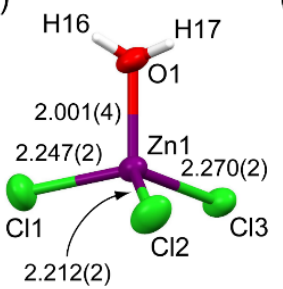

(e)

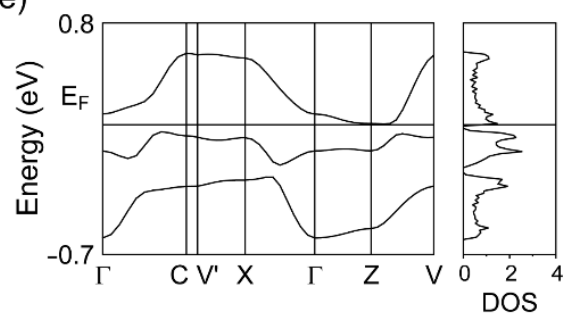

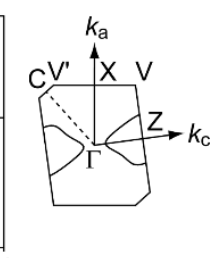

Figure 10. (a) Molecular arrangement of ET molecules at $y \sim 0.5$ in $(\mathrm{ET})_{3}\left[\mathrm{ZnCl}_{3}\left(\mathrm{H}_{2} \mathrm{O}\right)\right]_{2}\left(\mathrm{H}_{2} \mathrm{O}\right)_{2}(\mathbf{8})$ at $298 \mathrm{~K}$. The overlap integrals $\left(\times 10^{-3}\right)$ are $\mathrm{p} 1=3.7, \mathrm{p} 2=-3.7$, $\mathrm{p} 3=-3.4, \mathrm{q} 1=7.5, \mathrm{q} 2=14.7, \mathrm{q} 3=-6.3$, and $\mathrm{q} 4=20.6$. Ring-over-bond-type overlap patterns of adjacent ET molecules (b) between $\mathbf{A}$ and $\mathbf{B}$ and (c) between $\mathbf{A}$ and $\mathbf{A}$. (d) Molecular structure of $\mathrm{ZnCl}_{3}\left(\mathrm{H}_{2} \mathrm{O}\right)^{-}$ion. (e) Band dispersion, density of states (DOS), and Fermi surface of the HOMO band of ET, calculated by assuming the uniform charge distribution in the ET layer (i.e. +0.67 e on each ET). Horizontal lines at $E_{\mathrm{F}}$ indicate the Fermi level. 
(a)

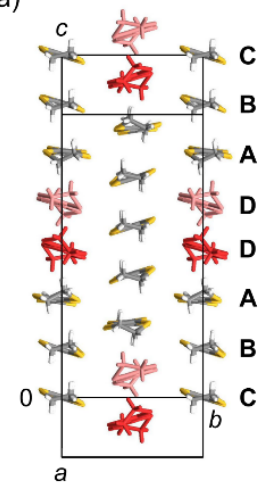

(c)

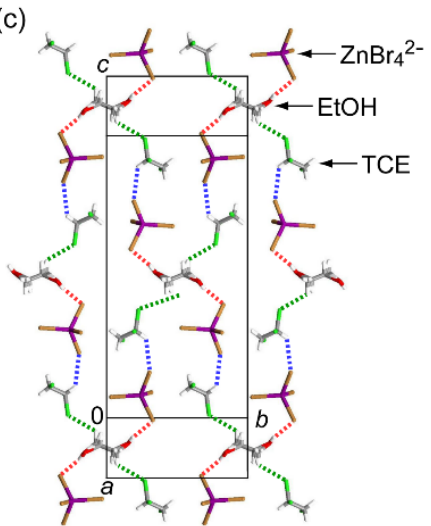

(b)

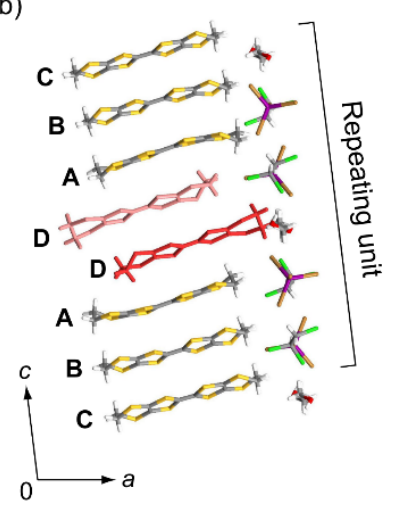

(d)

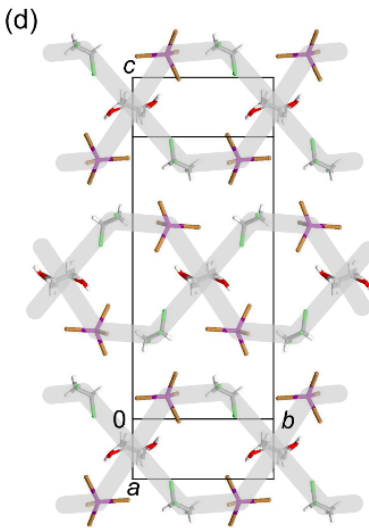

(e)
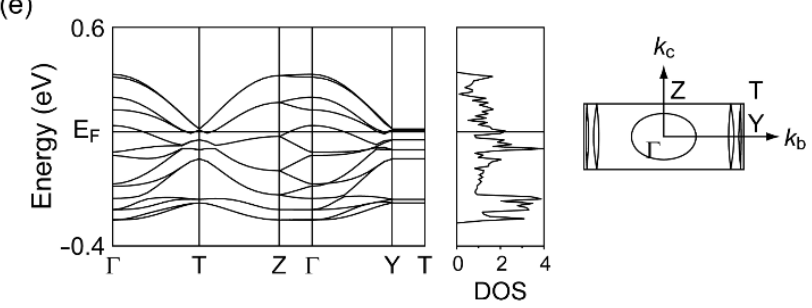

(f)
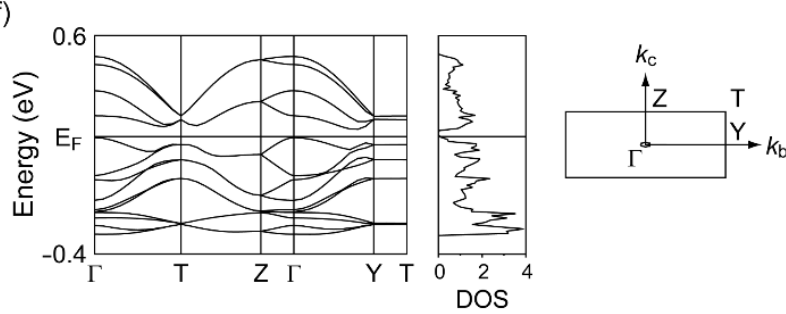

Figure 11. (a) Molecular arrangement of ET in (ET) $)_{7}\left(\mathrm{ZnBr}_{4}\right)_{2}(\mathrm{TCE})_{2}(\mathrm{EtOH})(9)$ within the $b c$ plane at $x \sim 0$. See text for red- and pink-painted ET molecules. (b) Column of ET molecules and molecules in an adjacent anionic layer viewed along the $b$ axis. (c) Molecular arrangement of $\mathrm{ZnBr}_{4}{ }^{2-}$, TCE, and disordered EtOH within the $b c$ plane at $x \sim 0.5$, where red, blue, and green dotted lines show $\mathrm{H} 1 \cdots \mathrm{Br} 4, \mathrm{H} 42 \cdots \mathrm{Br} 2$, and $\mathrm{H} 51 \mathrm{~A} \cdots \mathrm{Cl} 3$ hydrogen bonds, respectively. (d) Hexagonal cavities (grey thick lines) surrounded by two $\mathrm{ZnBr}_{4}{ }^{2-}$, two TCE, and two EtOH. Band dispersion, DOS, and Fermi surface of the HOMO band of ET, calculated assuming the uniform charge distribution in the ET layer (i.e. $+0.57 \mathrm{e}$ on each ET) at (e) $298 \mathrm{~K}$ and (f) $100 \mathrm{~K}$. Horizontal lines at $E_{\mathrm{F}}$ indicate the Fermi level. 
(a)

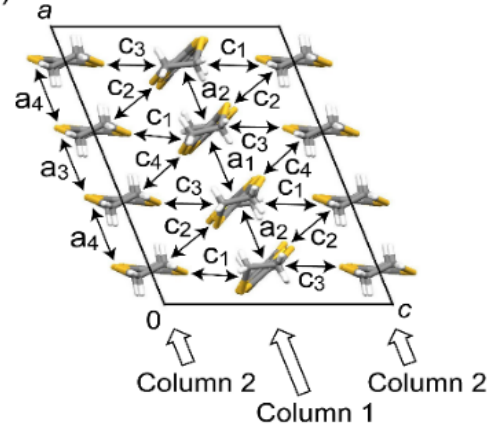

(c)

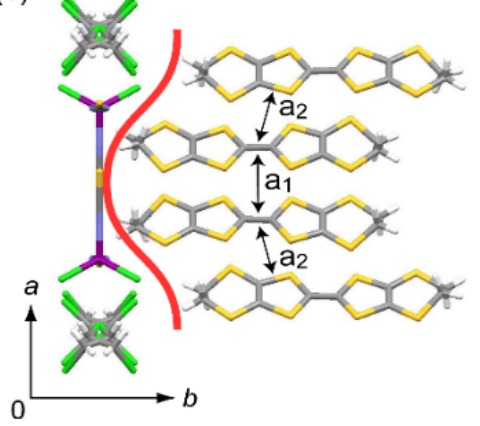

(b)

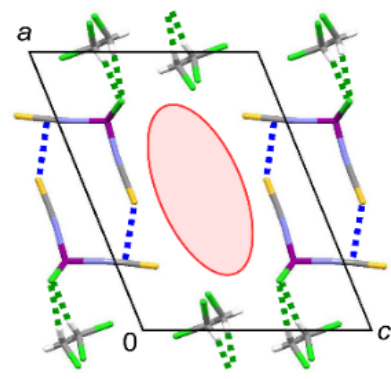

(d)

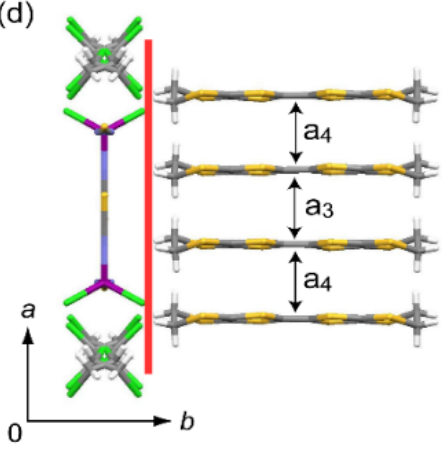

(e)

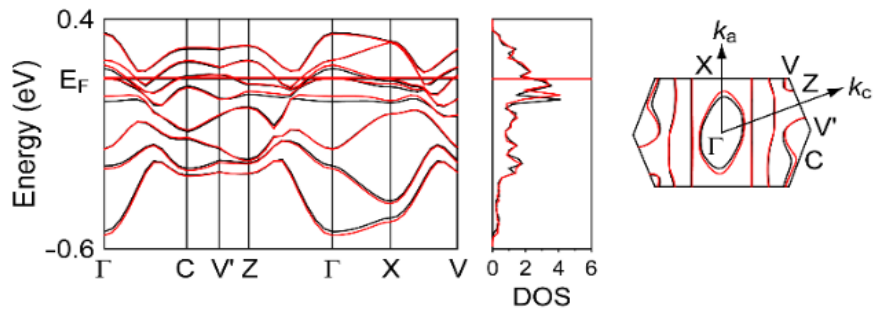

Figure 12. (a) Molecular arrangement within the $a c$ plane for (a) ET molecules (grey: C, white: H, orange: S) at $y \sim 0.25$ and (b) anion and TCE molecules (grey: C, white: $\mathrm{H}$, green: $\mathrm{Cl}$ ) at $y \sim 0$ in $\theta_{42+40}-(\mathrm{ET})_{4} \mathrm{Zn}(\mathrm{NCS})_{2} \mathrm{Cl}_{2}$ (TCE) (10) at $100 \mathrm{~K}$. The overlap integrals $\left(\times 10^{-3}\right)$ of 10 (values in parentheses are for $\theta_{42+40}-(\mathrm{ET})_{4} \mathrm{Zn}(\mathrm{NCS})_{2} \mathrm{Br}_{2}$ (TCE) (11)) at $298 \mathrm{~K}$ are a1 $=-2.8$ (-1.9), a2 = -4.1 (-3.7), a3 = -5.3 (-4.9), a4 = -4.0 (-4.2), c1 = -6.6 (-6.4), c2 = 6.8 (6.9), c3 $=-6.7(-6.4)$, and c4 $=7.5$ (7.6). Blue and green dotted lines in (b) indicate short S $\cdots \mathrm{C}$ and $\mathrm{C}-\mathrm{H} \cdots \mathrm{Cl}$ contacts, respectively. A red ellipse in (b) indicates the cavity surrounded by four $\mathrm{Zn}(\mathrm{NCS})_{2} \mathrm{Cl}_{2}{ }^{2-}$ and four TCE, which results in the zig-zag arrangement of ET dimers in Column 1 along the $a$ axis (c). Molecular arrangement of ET in (c) Column 1 and (d) Column 2 along the $a$ axis. Red lines show the schematic boundary between ET and anionic layers. (e) Calculated band dispersion, DOS, and Fermi surface of the HOMO band of ET in $\mathbf{1 0}$ (red) and 11 (black) at $298 \mathrm{~K}$. Horizontal lines at $E_{\mathrm{F}}$ indicate the Fermi level. 
Figure 13. (a) Temperature dependence of $\rho$ of a single crystal of 10-12 in Group D during the cooling process. The arrows indicate the maximum slope of the curves. Inset: Variation of critical temperatures ( $\left.T_{0}\right)$ with $a c \sin \beta$ for 10 (red), 11 (blue), and 12 (green). Circles and triangles represent the temperatures estimated on the basis of the temperature dependence of the resistivity (arrows) and the intensity of the superlattice reflections (Fig. S2 in Supporting Information). (b) Raman spectra of 10 in the range of $1300-1600 \mathrm{~cm}^{-1}$ at 67 and $250 \mathrm{~K}$. 


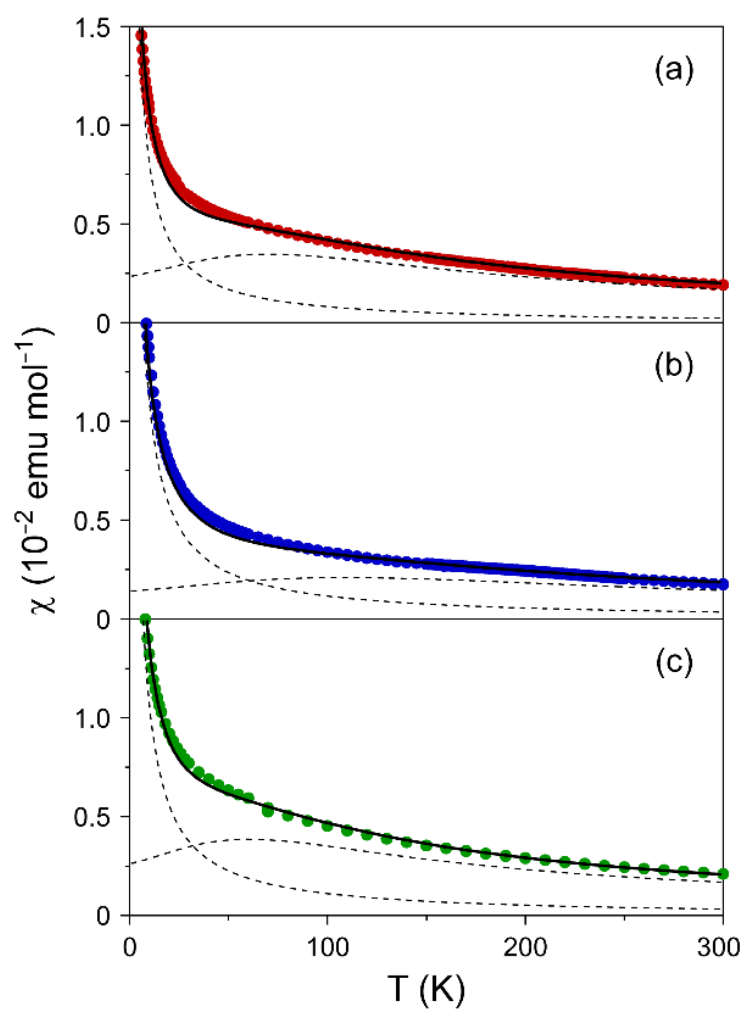

Figure 14. Temperature dependence of $\chi$ of polycrystalline samples of (a) 10, (b) 11, and (c) 12 in Group $\mathbf{D}$ in an applied magnetic field of $1 \mathrm{~T}$. Two dotted lines showing a broad maximum at a certain temperature and a divergence at low temperatures represent the calculated susceptibilities for the Heisenberg AF linear chain model ${ }^{58,59}$ and for the Curie model, respectively. Solid lines indicate the fitting results, which comprise each of the two components. 
(a)

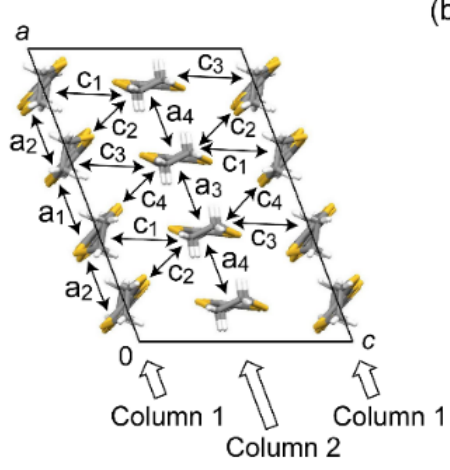

(c)

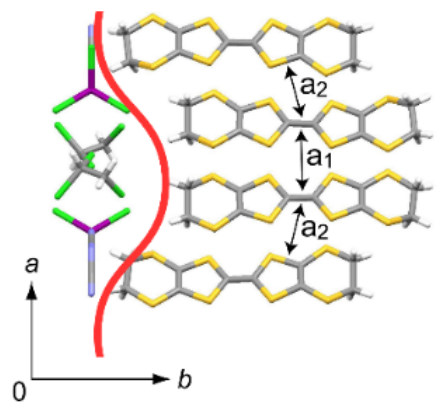

(b)

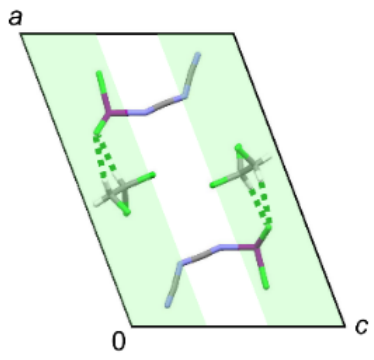

(d)

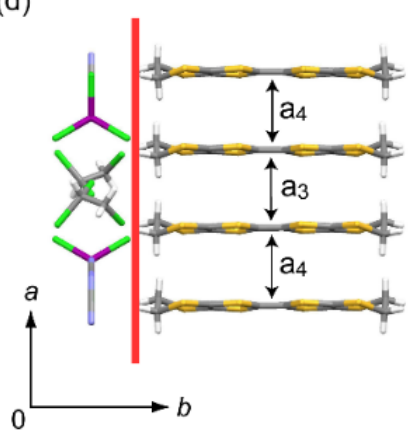

(e)

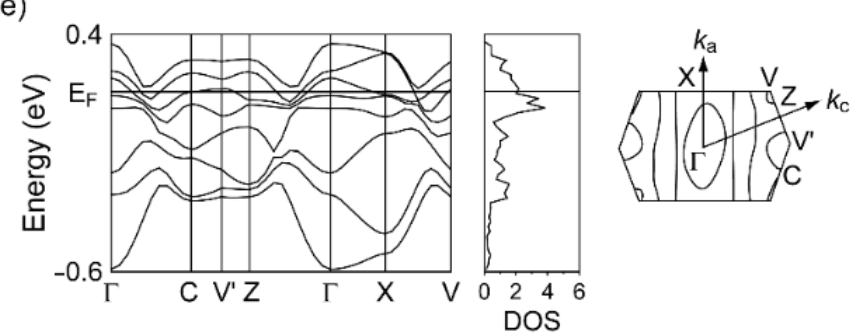

Figure 15. Molecular arrangement within the $a c$ plane for (a) ET molecules at $y \sim 0.25$ and (b) anion and TCE molecules at $y \sim 0$ in $\theta_{42+40}(\mathrm{ET})_{4} \mathrm{Zn}\left[\mathrm{N}(\mathrm{CN})_{2}\right] \mathrm{Cl}_{3}(\mathrm{TCE})(\mathbf{1 2})$ at $298 \mathrm{~K}$. The overlap integrals $\left(\times 10^{-3}\right)$ are $\mathrm{a} 1=-4.2, \mathrm{a} 2=-5.3, \mathrm{a} 3=-4.5, \mathrm{a} 4=-4.1, \mathrm{c} 1=-7.7, \mathrm{c} 2=7.2, \mathrm{c} 3$ $=-7.1$, and $\mathrm{c} 4=8.0$. Pale green areas in (b) show the existing area of chlorides projecting from the plane, which results in the zig-zag arrangement of ET dimers in Column 1 along the $a$ axis (c). Molecular arrangement of ET in (c) Column 1 and (d) Column 2 along the $a$ axis. Red lines show the schematic boundary between ET and anionic layers. (e) Calculated band dispersion, DOS, and Fermi surface of the HOMO band of ET at $298 \mathrm{~K}$. Horizontal lines at $E_{\mathrm{F}}$ indicate the Fermi level. 


\section{For Table of Contents Use Only}

Title: BEDT-TTF Salts Formed with Tetrahedrally Coordinated Zinc(II) Complex Anions

Authors: Yukihiro Yoshida, Hiroshi Ito, Yuto Nakamura, Manabu Ishikawa, Akihiro Otsuka, Hiromi Hayama, Mitsuhiko Maesato, Hideki Yamochi, Hideo Kishida, and Gunzi Saito

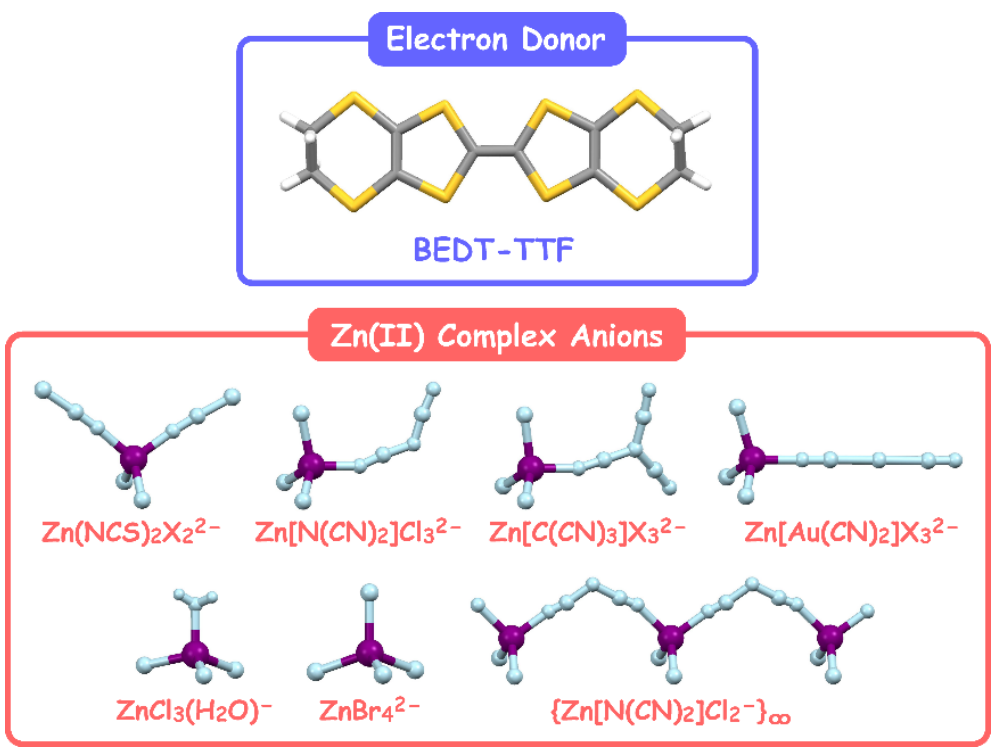

12 kinds of BEDT-TTF cation salts with various structural, charge, and physical properties were electrochemically obtained by combining with tetrahedrally coordinated zinc(II) complex anions. 


\title{
Supporting Information
}

\section{BEDT-TTF Salts Formed with Tetrahedrally Coordinated Zinc(II) Complex Anions}

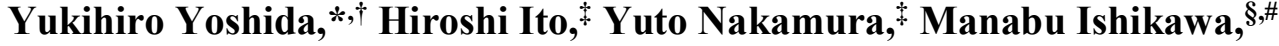 \\ Akihiro Otsuka, ${ }^{\S}, \#$ Hiromi Hayama, ${ }^{\dagger}$ Mitsuhiko Maesato, ${ }^{\S}$ \\ Hideki Yamochi, ${ }^{\S, \# ~ H i d e o ~ K i s h i d a, ~}{ }^{\ddagger}$ and Gunzi Saito ${ }^{\dagger, \|}$
}

${ }^{\dagger}$ Faculty of Agriculture, Meijo University, Tempaku-ku, Nagoya 468-8502, Japan

* Department of Applied Physics, Nagoya University, Chikusa-ku, Nagoya 464-8603, Japan

§ Division of Chemistry, Graduate School of Science, Kyoto University, Sakyo-ku, Kyoto 606-8502, Japan

\# Research Center for Low Temperature and Materials Sciences, Kyoto University, Sakyoku, Kyoto 606-8501, Japan

" Toyota Physical and Chemical Research Institute, Nagakute 480-1192, Japan 

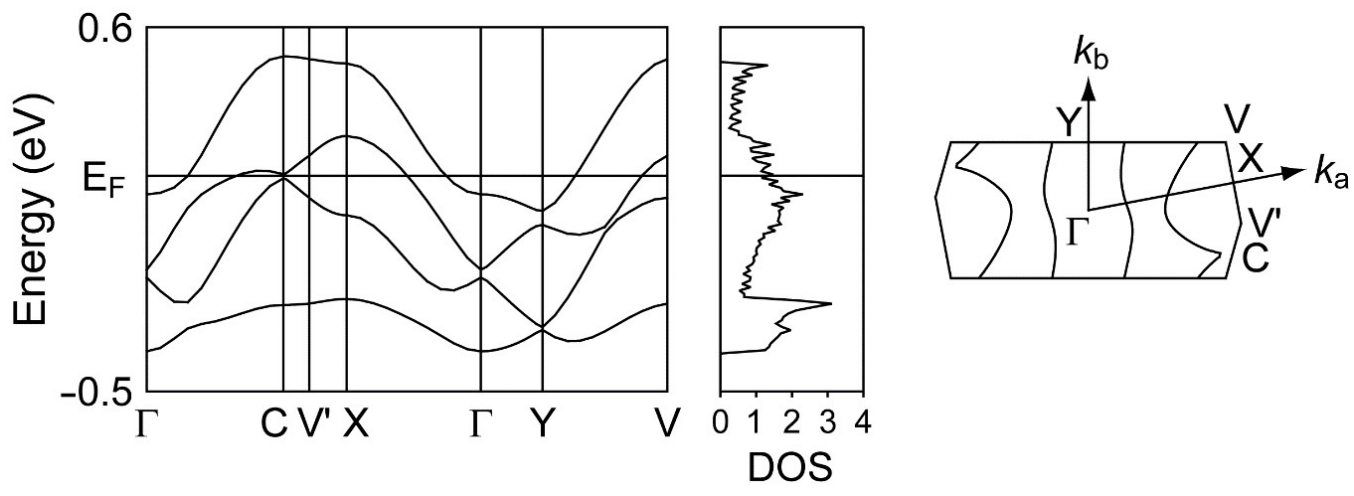

Figure S1. Band dispersion, density of states (DOS), and Fermi surface of the HOMO band of $\mathrm{ET}$ in $(\mathrm{ET})_{2} \mathrm{Zn}\left[\mathrm{N}(\mathrm{CN})_{2}\right] \mathrm{Cl}_{2}(\mathrm{TCE})_{0.5}(\mathbf{6})$ at $100 \mathrm{~K}$, calculated by assuming the uniform charge distribution in the ET layer (i.e. $+0.5 \mathrm{e}$ on each ET). Horizontal lines at $E_{\mathrm{F}}$ indicate the Fermi level. 

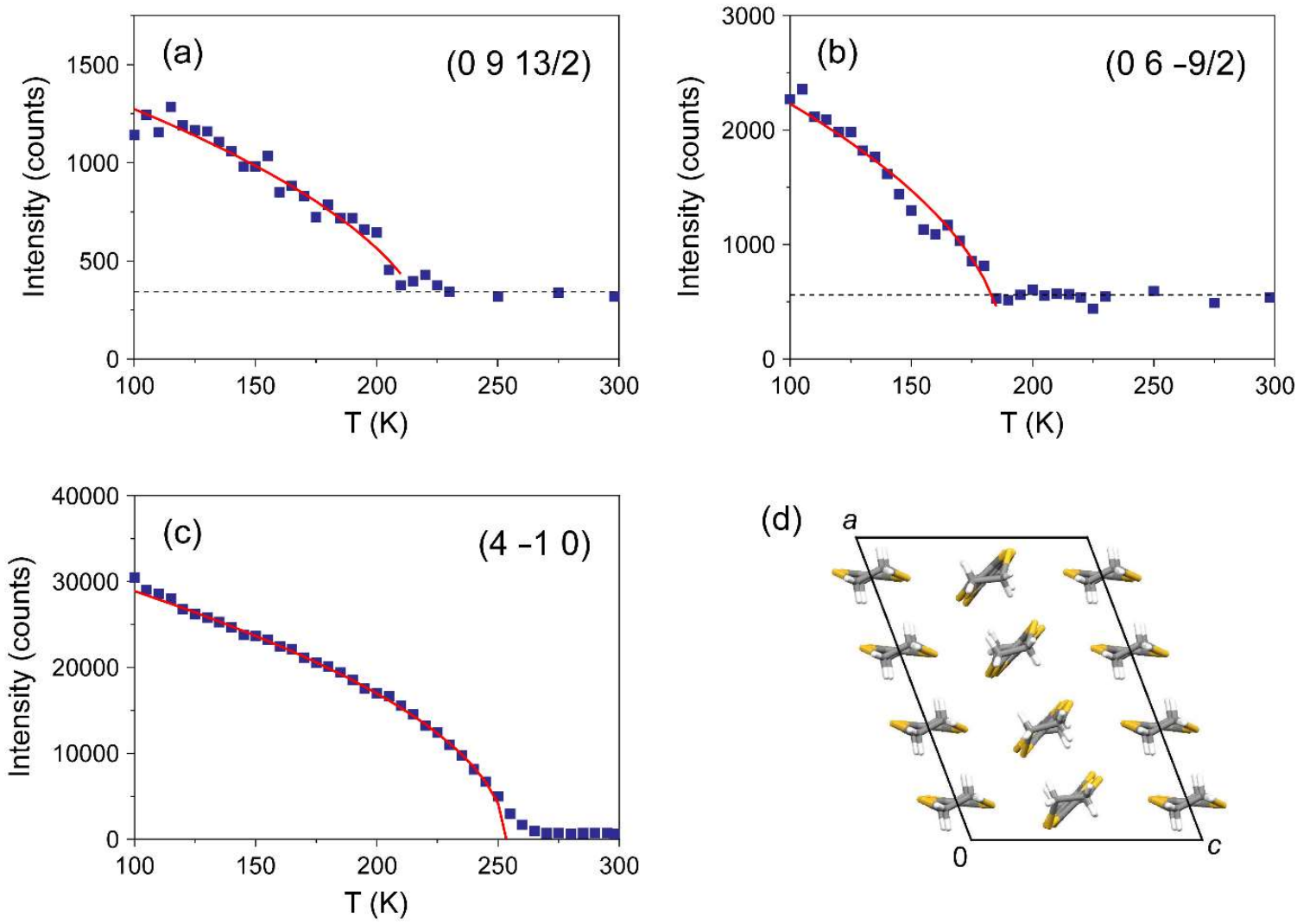

(d)

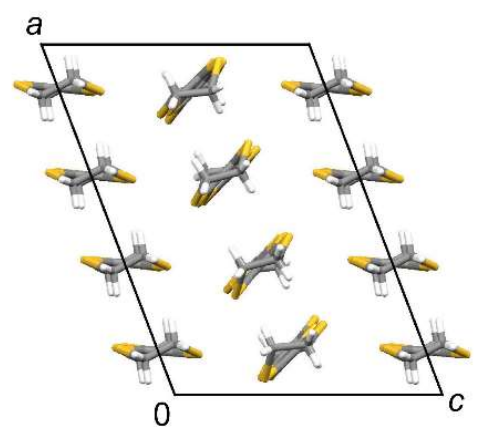

Figure S2. Temperature dependence of the intensity at the superlattice Bragg positions for (a) $\theta_{42+40}-(\mathrm{ET})_{4} \mathrm{Zn}(\mathrm{NCS})_{2} \mathrm{Cl}_{2}$ (TCE) (10), (b) $\theta_{42+40}-(\mathrm{ET})_{4} \mathrm{Zn}(\mathrm{NCS})_{2} \mathrm{Br}_{2}(\mathrm{TCE})(\mathbf{1 1})$, and (c) $\theta_{42+40-}(\mathrm{ET})_{4} \mathrm{Zn}\left[\mathrm{N}(\mathrm{CN})_{2}\right] \mathrm{Cl}_{3}(\mathrm{TCE})(\mathbf{1 2})$ on heating process. Red lines correspond to the fit using the equation $I \sim\left(T_{0}-T\right)^{1 / 2}$ for a second-order transition, where the $T_{0}$ values were estimated to be $224 \mathrm{~K}$ for $\mathbf{1 0}, 189 \mathrm{~K}$ for $\mathbf{1 1}$, and $253 \mathrm{~K}$ for $\mathbf{1 2}$. The superlattice reflections are indexed in terms of the RT structure. (d) Molecular arrangement of ET molecules within the ac plane for 10-12, where the unit cell corresponds to that at room temperature. 